\title{
Large-Scale Hydrogen Production from Nuclear Energy Using High Temperature Electrolysis
}

\section{IHTC 14}

James E. O'Brien

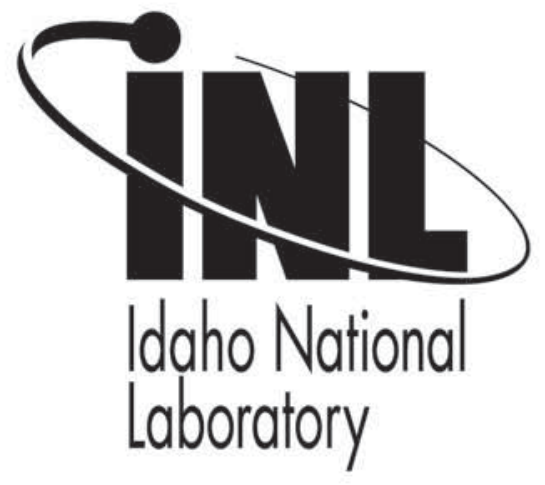

This is a preprint of a paper intended for publication in a journal or proceedings. Since changes may be made before publication, this preprint should not be cited or reproduced without permission of the author. This document was prepared as an account of work sponsored by an agency of the United States Government. Neither the United States Government nor any agency thereof, or any of their employees, makes any warranty, expressed or implied, or assumes any legal liability or responsibility for any third party's use, or the results of such use, of any information, apparatus, product or process disclosed in this report, or represents that its use by such third party would not infringe privately owned rights. The views expressed in this paper are not necessarily those of the United States Government or the sponsoring agency. 


\title{
LARGE SCALE HYDROGEN PRODUCTION FROM NUCLEAR ENERGY USING HIGH TEMPERATURE ELECTROLYSIS
}

\author{
James E. O'Brien \\ Idaho National Laboratory \\ Idaho Falls, ID, USA
}

\begin{abstract}
Hydrogen can be produced from water splitting with relatively high efficiency using high-temperature electrolysis. This technology makes use of solid-oxide cells, running in the electrolysis mode to produce hydrogen from steam, while consuming electricity and high-temperature process heat. When coupled to an advanced high temperature nuclear reactor, the overall thermal-to-hydrogen efficiency for high-temperature electrolysis can be as high as $50 \%$, which is about double the overall efficiency of conventional low-temperature electrolysis. Current large-scale hydrogen production is based almost exclusively on steam reforming of methane, a method that consumes a precious fossil fuel while emitting carbon dioxide to the atmosphere. Demand for hydrogen is increasing rapidly for refining of increasingly low-grade petroleum resources, such as the Athabasca oil sands and for ammonia-based fertilizer production. Large quantities of hydrogen are also required for carbon-efficient conversion of biomass to liquid fuels. With supplemental nuclear hydrogen, almost all of the carbon in the biomass can be converted to liquid fuels in a nearly carbon-neutral fashion. Ultimately, hydrogen may be employed as a direct transportation fuel in a "hydrogen economy." The large quantity of hydrogen that would be required for this concept should be produced without consuming fossil fuels or emitting greenhouse gases. An overview of the high-temperature electrolysis technology will be presented, including basic theory, modeling, and experimental activities. Modeling activities include both computational fluid dynamics and large-scale systems analysis. We have also demonstrated high-temperature electrolysis in our laboratory at the $15 \mathrm{~kW}$ scale, achieving a hydrogen production rate in excess of $5500 \mathrm{~L} / \mathrm{hr}$.
\end{abstract}

\section{INTRODUCTION}

There is an increasing level of interest in the development of large-scale non-fossil hydrogen production technologies. In terms of the transportation sector, this interest is driven by the near-term demand for hydrogen for refining of increasingly low-quality petroleum resources, the expected intermediateterm demand for carbon-neutral synthetic fuels, and the potential long-term demand for hydrogen as an environmentally benign direct transportation fuel [1-3]. Additional important non-transportation markets for large-scale hydrogen production include ammonia production and (potentially) carbon-free steel production [4]. At present, hydrogen production in North America is based almost exclusively on steam reforming of methane. From a long-term perspective, methane reforming may not be sustainable for large-scale hydrogen production since natural gas is a non-renewable resource that exhibits large volatility in price and since methane reforming and other fossilfuel conversion processes emit large quantities of greenhouse gases to the environment [5]. Non-fossil carbon-free options for hydrogen production include conventional water electrolysis coupled to either renewable (e.g., wind) energy sources or nuclear energy. The renewable-hydrogen option may be viable as a supplementary source, but would be very expensive as a large-scale stand-alone option [6, 7]. Conventional electrolysis coupled to nuclear base-load power can approach economical viability when combined with offpeak power, but the capital cost is high [8]. To achieve higher overall hydrogen production efficiencies, high-temperature thermochemical [9] or electrolytic [10] processes can be used. The required high temperature process heat can be based on concentrated solar energy [11] or on nuclear energy from advanced high-temperature reactors [12].

High-temperature nuclear reactors have the potential for substantially increasing the efficiency of hydrogen production from water, with no consumption of fossil fuels, no production of greenhouse gases, and no other forms of air pollution. Advanced nuclear hydrogen production can be accomplished via high-temperature electrolysis (HTE) or thermochemical processes, using high-temperature nuclear process heat [13]. In 


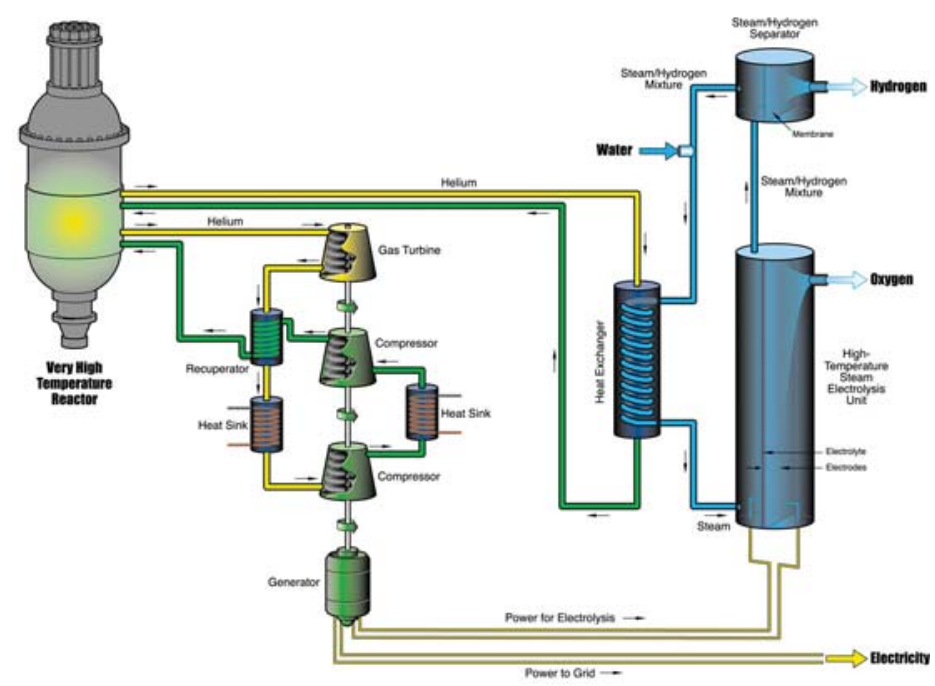

Figure 1. Concept for high-temperature electrolysis system coupled to an advanced nuclear reactor.

order to achieve their best efficiencies, these processes require high-temperature operation $\left(\sim 850^{\circ} \mathrm{C}\right)$ and are therefore tied to the development of advanced high-temperature nuclear reactors. A conceptual depiction of a high-temperature gascooled reactor coupled to a high-temperature electrolysis system is shown in Fig. 1. In this scheme, the primary helium coolant serves as the working fluid to drive a gas-turbine power cycle, which provides the electrical energy required for the high-temperature electrolysis process. In addition, some of the hot helium is used to deliver high-temperature nuclear process heat directly to the endothermic HTE process. Hightemperature electrolytic water-splitting supported by nuclear process heat and electricity has the potential to produce hydrogen with overall thermal-to-hydrogen efficiencies of 50\% or higher, based on high heating value. This efficiency is similar to that of the thermochemical processes $[14,15]$, but without the severe corrosive conditions of the thermochemical processes and without the fossil fuel consumption and greenhouse gas emissions associated with hydrocarbon processes. Furthermore, based on a detailed life-cycle analysis (LCA) [16], nuclear HTE is far superior to the conventional steam reforming process for hydrogen production with respect to global warming and acidification potential. Life cycle analyses of nuclear power generation have reached similar conclusions, according to a series of papers [e.g., 17] produced by the EC-sponsored ExternE project. Another recent study at Stanford [18] recognized the potential contribution of nuclear energy in the context of global warming and air pollution external costs. However, this study assigned a certain elevated risk of nuclear war associated with the development of nuclear energy, which resulted in a low overall ranking for nuclear.

From 2003 - 2009, development and demonstration of advanced nuclear hydrogen technologies were supported by the US Department of Energy under the Nuclear Hydrogen Initiative [19]. During 2009, this program sponsored a technology down-selection activity by which an independent review team recommended HTE as the most appropriate advanced nuclear hydrogen production technology for nearterm deployment [20].

The INL HTE program also includes an investigation of the feasibility of direct syngas production by simultaneous electrolytic reduction of steam and carbon dioxide (coelectrolysis) at high temperature using solid-oxide cells. Syngas, a mixture of hydrogen and carbon monoxide, can be used for the production of synthetic liquid fuels via FischerTropsch or other synthesis processes. This concept, coupled with nuclear energy, provides a possible path to reduced greenhouse gas emissions and increased energy independence, without the major infrastructure shift that would be required for a purely hydrogen-based transportation system [21- 24]. Furthermore, if the carbon dioxide feedstock is obtained from biomass, the entire concept would be climate-neutral.

As an alternative to centralized large-scale systems with direct coupling to high-temperature reactors, distributed hydrogen production could be accomplished using modular HTE units powered from grid electricity and an alternate hightemperature heat source such as concentrated solar energy [25] or a biomass gasifier [26]. This approach could be quite economical if off-peak electricity is used [27].

This paper will provide an overview of high-temperature electrolysis as a potential method for efficient carbon-free large-scale hydrogen production.

\section{NOMENCLATURE}

ASR area-specific resistance, $\mathrm{Ohm} \cdot \mathrm{cm}^{2}$

$Q \quad$ heat, $\mathrm{J}$

q" heat flux, $\mathrm{W} / \mathrm{cm}^{2}$

T temperature, ${ }^{\circ} \mathrm{C}$

$P \quad$ pressure, $\mathrm{kPa}$

$\triangle S \quad$ entropy change, $\mathrm{J} / \mathrm{mol} \mathrm{K}$

$\Delta H \quad$ enthalpy change, $\mathrm{J} / \mathrm{mol}$

$\eta_{H} \quad$ overall thermal-to-hydrogen efficiency

$\eta_{e} \quad$ electrolysis efficiency

HHV high heating value, $\mathrm{J} / \mathrm{mol}$

LHV low heating value, $\mathrm{J} / \mathrm{mol}$

$\Delta G \quad$ gibbs energy change, $\mathrm{J} / \mathrm{mol}$

$W \quad$ work, $\mathrm{J}$

F $\quad$ Faraday number

$j \quad$ moles of electrons transferred/mole hydrogen

I electrical current, A

I current density, $\mathrm{A} / \mathrm{cm}^{2}$

$V \quad$ voltage, $\mathrm{V}$

$\dot{N} \quad$ molar rate, $\mathrm{mol} / \mathrm{s}$

$y \quad$ mole fraction

\section{PERFORMANCE LIMITS FOR THERMAL WATER SPLITTING PROCESSES}

A basic thermodynamic analysis can be applied to a general thermal water-splitting process in order to determine overall process efficiency limits as a function of temperature. Consider the process diagram for thermal water splitting shown in Fig. 2. Water enters the control volume from the left. Since the feedstock for any large-scale water-splitting operation will 


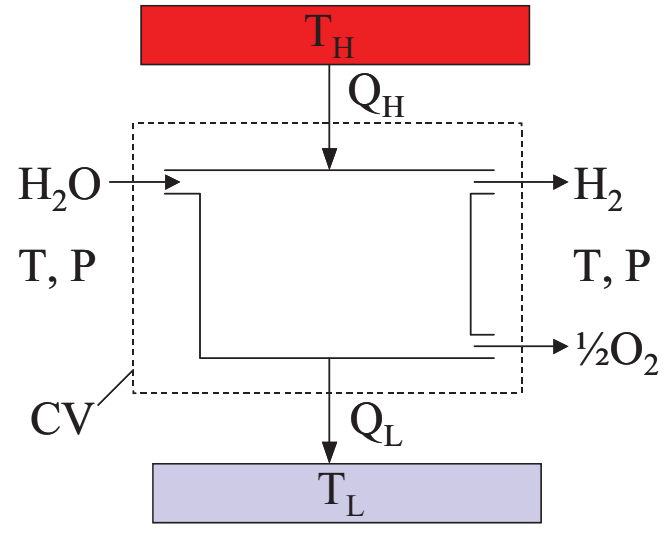

Figure 2. Schematic of a generic thermal water-splitting process operating between temperatures $T_{H}$ and $T_{L}$.

be liquid water, it is reasonable to consider the case in which water enters the control volume in the liquid phase at a specified temperature $\mathrm{T}$ and pressure $\mathrm{P}$, typically near ambient conditions. Pure hydrogen and oxygen streams exit the control volume on the right, also at $\mathrm{T}$ and $\mathrm{P}$. Two heat reservoirs are available, a high-temperature reservoir at temperature $T_{H}$ and a low-temperature reservoir at temperature $T_{L}$. Heat transfer between these reservoirs and the control volume is indicated in the figure as $Q_{H}$ and $Q_{L}$. Note that there is no work crossing the control-volume boundary. Therefore if the process under consideration is high-temperature electrolysis, both the power cycle (based on a heat engine) and the electrolyzer are located inside the control volume.

From an overall chemical reaction standpoint, the watersplitting process corresponds to the dissociation or reduction of water:

$$
\mathrm{H}_{2} \mathrm{O} \rightarrow \mathrm{H}_{2}+1 / 2 \mathrm{O}_{2}
$$

The first and second laws of thermodynamics can be applied to this process as follows:

$$
\begin{array}{ll}
\text { 1st law: } & Q_{H}-Q_{L}=\Delta H_{R} \\
\text { 2nd law: } & \Delta S_{R} \geq \frac{Q_{H}}{T_{H}}-\frac{Q_{L}}{T_{L}}
\end{array}
$$

where $\Delta H_{R}$ is the enthalpy of reaction and $\Delta S_{R}$ is the entropy change of the reaction. The overall thermal-to-hydrogen efficiency of thermal water splitting processes can be defined in terms of the net enthalpy increase of the reaction products over the reactants (can also be thought of as the energy content or heating value of the produced hydrogen), divided by the hightemperature heat added to the system:

$$
\eta_{H}=\frac{\Delta H_{R}}{Q_{H}}
$$

Combining the first and second law equations for the reversible case and substituting into the efficiency definition yields:

$$
\eta_{H, \max }=\frac{1-T_{L} / T_{H}}{1-T_{L} \Delta S_{R} / \Delta H_{R}}
$$

Note that the water splitting process defined in Fig. 2 is simply the reverse of the combustion reaction of hydrogen with oxygen. Therefore the enthalpy of reaction for the watersplitting process is the opposite of the enthalpy of combustion, which by definition is equal to the "heating value" of the hydrogen. Since for our process, we have assumed that the water enters the control volume in the liquid phase,

$$
\Delta H_{R}=H H V
$$

where HHV is the "high heating value" of hydrogen. If we further assume that $\mathrm{T}$ and $\mathrm{P}$ represent standard conditions, and that $T_{L}=T^{\circ}$,

$$
\Delta H_{R}-T_{L} \Delta S_{R}=-\Delta G_{f, H_{2} O}^{o}
$$

such that the efficiency expression can be rewritten as:

$\eta_{H, \max }=\left(1-\frac{T_{L}}{T_{H}}\right)\left(\frac{H H V}{-\Delta G_{f, H_{2} O}^{O}}\right)=\left(1-\frac{T_{L}}{T_{H}}\right)\left(\frac{1}{0.83}\right)$

The high heating value of the hydrogen and the standard-state Gibbs energy of formation for water are fixed quantities such that the second factor on the right-hand side is a constant. This efficiency limit has also been derived for the sulfur-iodine thermochemical process based on an exergy analysis [28].

Comparing Eq. (8) to Eq. (4), the high-temperature heat requirement for the process can be stated as:

$$
Q_{H} \geq \frac{T_{H}}{T_{H}-T_{L}}\left(-\Delta G_{f, H_{2} O}^{O}\right)
$$

This result was derived for thermochemical cycles by Abraham and Schreiner [29], and applied to solar thermal dissociation of water by Fletcher and Moen [30], who noted that the maximum efficiencies of all thermochemical processes can be related to the efficiencies of Carnot engines operating between the same upper and lower temperatures. It is necessary only to add, conceptually, a reversible fuel cell which converts the hydrogen and oxygen to liquid water at the lower temperature, performing an amount of electrical work given by the Gibbs free energy of the reaction.

A plot of thermal water splitting efficiencies is presented in Fig. 3 for $T_{L}=20^{\circ} \mathrm{C}$. The top curve represents the maximum possible water-splitting efficiency result given by Eq. (8). The exergetic efficiency of the thermal water splitting process is given by the ratio of the actual efficiency to the maximum possible efficiency. A reasonable value to assume for exergetic efficiency is $65 \%$, which is represented by the bottom curve in Fig. 3. The $65 \%$ value is based on a typical percentage of Carnot efficiency that can be achieved with a well engineered modern power cycle. The first conclusion to be drawn is that high temperature is favorable for efficient hydrogen production based on thermal water splitting, regardless of the specific method used. If we assume that $65 \%$ of the maximum possible efficiency might also be achievable with a well engineered thermal water-splitting process, then efficiencies of the magnitude given in the lower curve of Fig. 3 should be expected. 


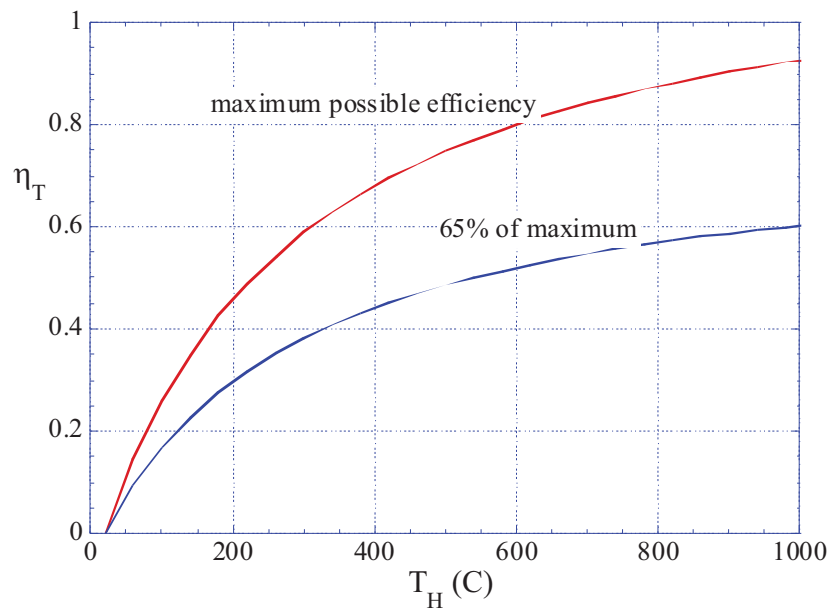

Figure 3. Theoretical thermal water splitting efficiencies.

Detailed process analyses have been performed [15] to analyze HTE-based hydrogen- production systems coupled to advanced nuclear reactors. Results from this study are presented in Fig. 4. This figure shows overall hydrogen production efficiencies, based on high heating value, plotted as a function of reactor outlet temperature. The figure includes the curve that represents $65 \%$ of the thermodynamic maximum efficiency, again assuming $T_{L}=20^{\circ} \mathrm{C}$. Three different advanced-reactor/power-conversion combinations were considered: a helium-cooled reactor coupled to a direct recuperative Brayton cycle, a supercritical $\mathrm{CO}_{2}$-cooled reactor coupled to a direct recompression cycle, and a sodium-cooled fast reactor coupled to a Rankine cycle. The system analyses were performed using UniSim [31] software. Each reactor/power-conversion combination was analyzed over an appropriate reactor outlet temperature range. The figure shows results for both HTE and low-temperature electrolysis (LTE). Results of system analyses performed at MIT [14] are also shown. The lower MIT curve, labeled MIT-GT-MHR/HTE

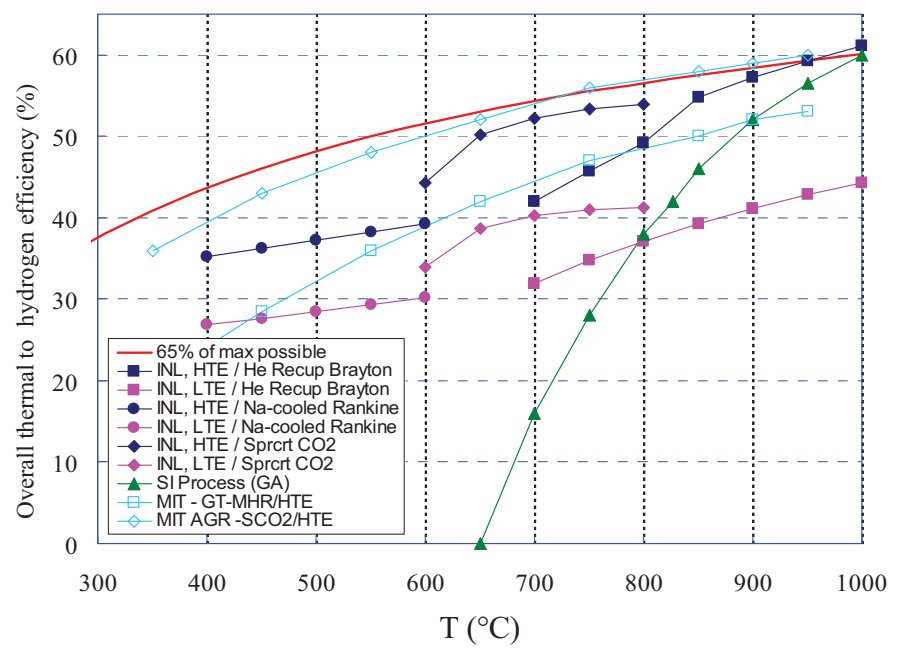

Figure 4. Overall thermal-to-hydrogen production efficiencies based on HHV for several reactor/process concepts, as a function of reactor outlet temperature. represents overall efficiency predictions for a helium-cooled reactor with a direct Brayton cycle power conversion unit. The upper MIT curve, labeled MIT-AGR-SCO2/HTE represents overall efficiency predictions for a $\mathrm{CO}_{2}$-cooled advanced gas reactor with a supercritical $\mathrm{CO}_{2}$ power conversion unit. For reactor outlet temperatures of $600-800^{\circ} \mathrm{C}$, the supercritical $\mathrm{CO}_{2} /$ recompression power cycle is superior to the Hecooled/Brayton cycle concept. This conclusion is consistent with results presented in reference [14]. Finally, an efficiency curve for the SI thermochemical process [32] is also shown. The results presented in Fig. 4 indicate that, even when detailed process models are considered, with realistic component efficiencies, heat exchanger performance, and operating conditions, overall hydrogen production efficiencies in excess of $50 \%$ can be achieved for HTE with reactor outlet temperatures above $850^{\circ} \mathrm{C}$. The efficiency curve for the SI process also includes values above $50 \%$ for reactor outlet temperatures above $900^{\circ} \mathrm{C}$, but it drops off quickly with decreasing temperature, and falls below values for LTE coupled to high-temperature reactors for outlet temperatures below $800^{\circ} \mathrm{C}$. Note that even LTE benefits from higher reactor outlet temperatures because of the improved power conversion thermal efficiencies associated with higher reactor outlet temperatures. Current planning for the Next Generation Nuclear Plant (NGNP) [12] indicates that reactor outlet temperatures will be at or below $800^{\circ} \mathrm{C}$, which favors HTE.

\section{THERMODYNAMICS OF HIGH TEMPERATURE ELECTROLYSIS}

Focusing specifically now on electrolysis, consider a control volume surrounding an isothermal electrolysis process, as shown in Fig. 5. In this case, both heat and work interactions cross the control volume boundary. The first law for this process is given by:

$$
Q-W=\Delta H_{R}
$$

For reversible operation,

$$
Q_{\text {rev }}=T \Delta S_{R}
$$

Such that

$$
W_{\text {rev }}=\Delta H_{R}-T \Delta S_{R}=\Delta G_{R}
$$

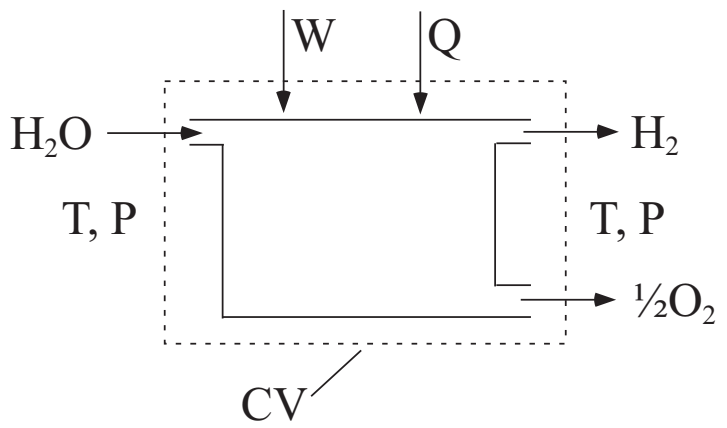

Figure 5. Schematic of a water electrolysis process operating at temperature $\mathrm{T}$. 


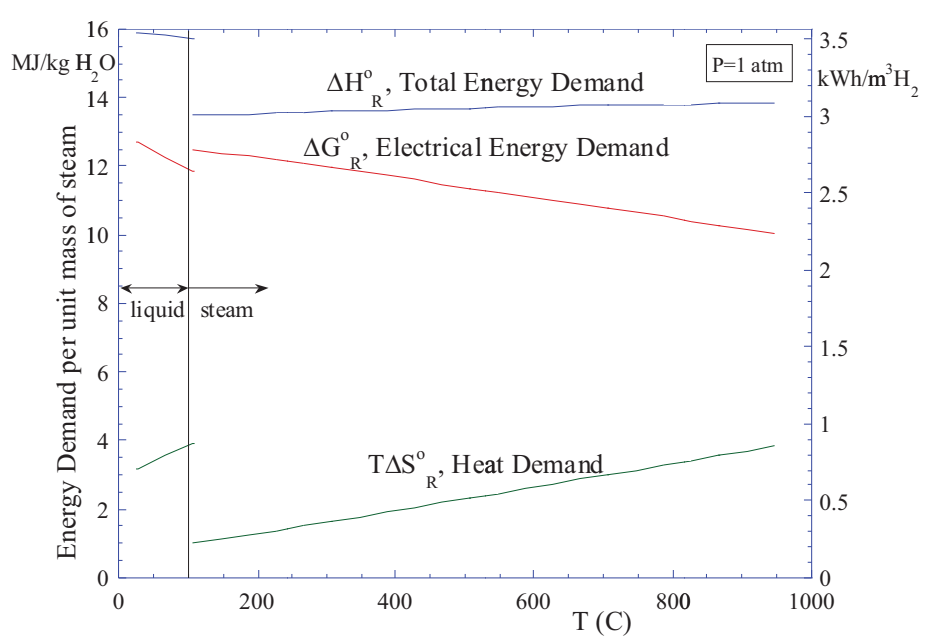

Fig. 6. Standard-state ideal energy requirements for electrolysis as a function of temperature.

The thermodynamic properties appearing in Eq. (12) are plotted in Fig. 6 as a function of temperature for the $\mathrm{H}_{2}-\mathrm{H}_{2} \mathrm{O}$ system from $0^{\circ} \mathrm{C}$ to $1000^{\circ} \mathrm{C}$ at standard pressure. This figure is often cited as a motivation for high-temperature electrolysis versus low-temperature electrolysis. It shows that the Gibbs free energy change, $\Delta G_{R}$, for the reacting system decreases with increasing temperature, while the product of temperature and the entropy change, $T \Delta S_{R}$, increases. Therefore, for reversible operation, the electrical work requirement decreases with temperature, and a larger fraction of the total energy required for electrolysis, $\Delta H_{R}$, can be supplied in the form of heat, represented by $T \Delta S_{R}$. Since heat-engine-based electrical work is limited to a thermal efficiency of $50 \%$ or less, decreasing the work requirement results in higher overall thermal-to-hydrogen production efficiencies. Note that the total energy requirement, $\Delta H_{R}$, increases only slightly with temperature, and is very close in magnitude to the lower heating value of hydrogen. The ratio of $\Delta G_{R}$ to $\Delta H_{R}$ is about $93 \%$ at $100^{\circ} \mathrm{C}$, decreasing to only about $70 \%$ at $1000^{\circ} \mathrm{C}$.

Operation of the electrolyzer at high temperature is also desirable from the standpoint of reaction kinetics and electrolyte conductivity, both of which improve dramatically at higher operating temperatures. The improved reaction kinetics at high temperature has the additional advantage that precious metal catalysts are not required. Potential disadvantages of high-temperature operation include the limited availability of very high temperature process heat and materials issues such as corrosion and degradation.

A cross sectional schematic of a solid-oxide electrolysis cell is provided in Fig. 7. As shown in the figure, a mixture of steam and hydrogen at $750-950^{\circ} \mathrm{C}$ is supplied to the cathode side of the electrolyte (note that cathode and anode sides are opposite to their fuel-cell-mode roles). The design depicted in the figure shows a nickel cermet cathode and a perovskite anode such as strontium-doped lanthanum manganite (LSM). The metallic "flow fields" conduct electrical current through the stack and provide flow passages for the process gas streams.

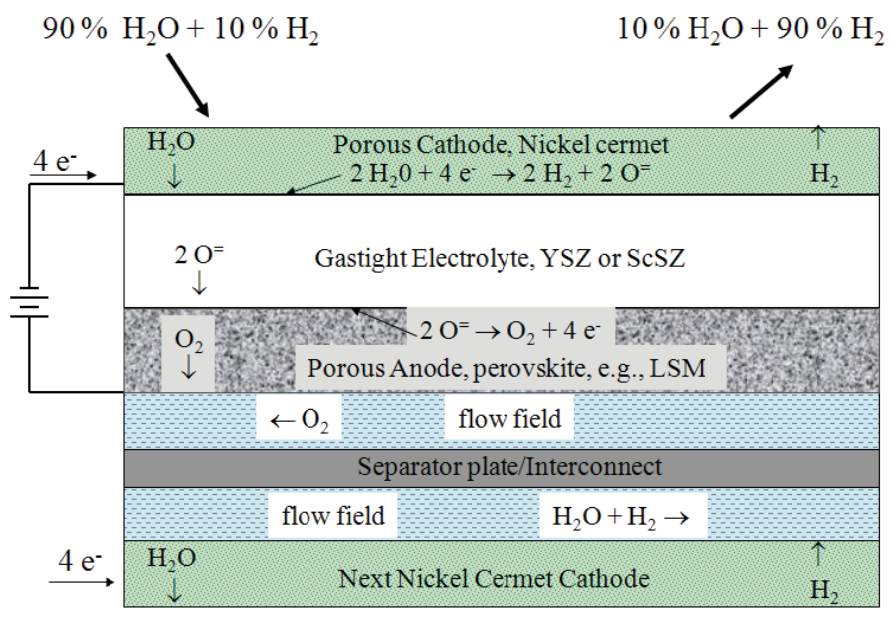

Figure 7. Cross-section of a planar high temperatur electrolysis stack.

The separator or bipolar plate separates the process gas streams. It must also be electrically conducting and is usually metallic, such as a ferritic stainless steel. The half-cell electrochemical reactions occur at the triple-phase boundary near the electrode/electrolyte interface, as shown in the figure. Oxygen ions are drawn through the electrolyte by an applied electrical potential. The ions liberate their electrons and recombine to form molecular $\mathrm{O}_{2}$ on the anode side. The inlet steamhydrogen mixture composition may be as much as $90 \%$ steam, with the remainder hydrogen. Hydrogen is included in the inlet stream in order to maintain reducing conditions at the cathode. The exiting mixture may be as much as $90 \% \mathrm{H}_{2}$. Product hydrogen and residual steam is passed through a condenser or membrane separator to purify the hydrogen.

In order to accomplish electrolysis, a voltage must be applied across the cell that is greater in magnitude than the open-cell potential. The standard-state open-cell potential is given by:

$$
V^{o}=\frac{\Delta G_{R}^{o}}{j F}
$$

where $j$ is the number of electrons transferred per molecule of hydrogen produced. For a solid-oxide system, in which $\mathrm{O}^{=}$ ions are transported through the electrolyte, $\mathrm{j}=2$. The standard-state open-cell potential applies to the case in which pure reactants and products are separated and at one standard atmosphere pressure. In most practical HTE systems, the incoming steam is mixed with some hydrogen and possibly some inert gas. Some inlet hydrogen is normally required in order to maintain reducing conditions on the steam-side electrode, typically a nickel cermet. Also, it is not desirable to run the electrolyzer to $100 \%$ steam utilization, because localized steam starvation will occur, severely degrading performance. Therefore, the outlet stream will include both hydrogen and steam. Residual steam can be removed from the product by condensation. On the oxygen-evolution side of the cells, air is often used as a sweep gas, so the oxygen partial pressure is only about $21 \%$ of the operating pressure. In addition, the electrolysis system can operate at elevated total 
pressure. In order to account for the range of gas compositions and pressures that occur in a real system, the open-cell (or Nernst) potential can be obtained from the Nernst equation, which can be written as:

$$
V_{N}=V^{o}-\frac{R_{u} T}{j F} \ln \left[\left(\frac{y_{H_{2} O}}{y_{H_{2}} y_{O_{2}}^{1 / 2}}\right)\left(\frac{P}{P_{s t d}}\right)^{-1 / 2}\right]
$$

Operation of a solid-oxide stack in the electrolysis mode is fundamentally different than operation in the fuel-cell mode for several reasons, aside from the obvious change in direction of the electrochemical reaction. From the standpoint of heat transfer, operation in the fuel-cell mode typically necessitates the use of significant excess air flow, well beyond what is required to support the electrochemical reaction, in order to prevent overheating of the stack. The potential for overheating arises from two sources: (1) the exothermic nature of the hydrogen oxidation reaction, and (2) ohmic heating associated with the electrolyte ionic resistance and other loss mechanisms.

Conversely, in the electrolysis mode, the steam reduction reaction is endothermic. Therefore, depending on the operating voltage, the net heat generation in the stack may be negative, zero, or positive. This phenomenon is illustrated in Fig. 8. The figure shows the respective internal heat sink/source fluxes in a planar solid-oxide stack associated with the electrochemical reaction and the ohmic heating. The ohmic heat flux $\left(\mathrm{W} / \mathrm{cm}^{2}\right)$ is given by:

$$
q^{\prime \prime}{ }_{\text {ohmic }}=i^{2} A S R=i\left(V_{o p}-V_{N}\right)
$$

where $i$ is the current density $\left(\mathrm{A} / \mathrm{cm}^{2}\right), A S R$ is the area-specific resistance $\left(\mathrm{Ohm} \cdot \mathrm{cm}^{2}\right)$, and $V_{N}$ is the mean Nernst potential for the operating cell. The reaction heat flux is given by:

$$
q^{\prime \prime}=\frac{i}{2 F}\left(T \Delta S_{e}\right)=\frac{i}{2 F}\left(\Delta G_{e}-\Delta H_{R}\right)
$$

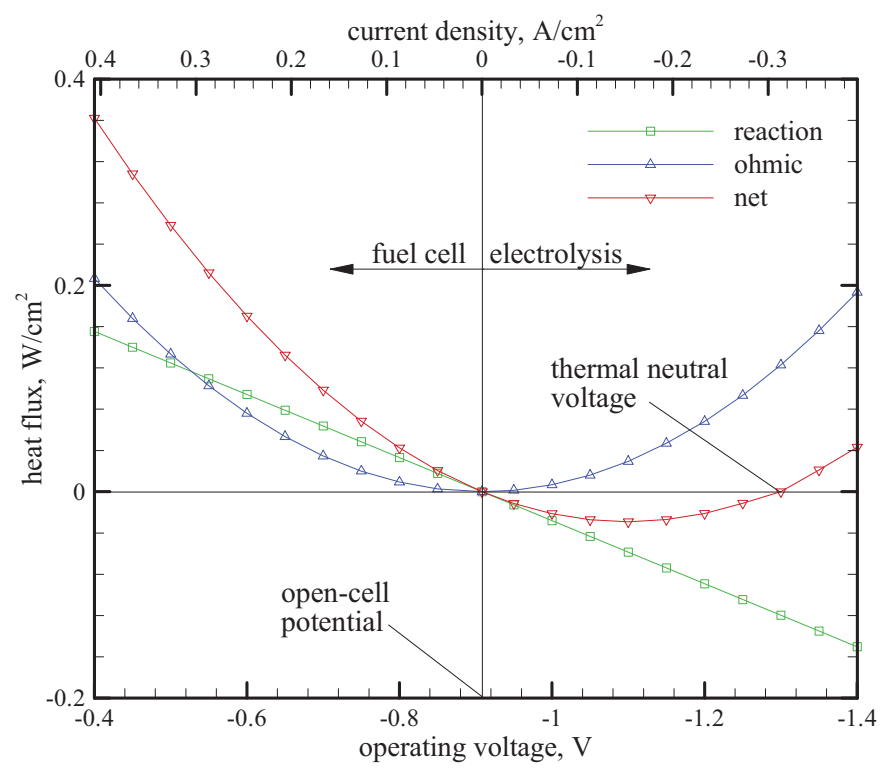

Figure 8. Thermal contributions in electrolysis and fuel cell modes of operation. where $\Delta S_{e}$ is the entropy change for the actual electrolysis process, accounting for the reactant and product partial pressures.

The net heat flux is also shown in Fig. 8. An $A S R$ value of $1.25 \mathrm{Ohm} \cdot \mathrm{cm}^{2}$, an operating temperature of $1200 \mathrm{~K}$, and fixed hydrogen mole fractions of 0.1 and 0.95 at the inlet and outlet, respectively, were assumed for these calculations. In the fuelcell mode, the net heat flux is always positive and increases rapidly with operating voltage and current density. In the electrolysis mode, the net heat flux is negative for low operating voltages, increases to zero at the "thermal-neutral" voltage, and is positive at higher voltages and current densities. The thermal-neutral voltage can be predicted from direct application of the rate-based First Law to the isothermal electrolysis system shown in Fig. 5:

$$
\dot{Q}-\dot{W}=\Delta \dot{N}_{H_{2}} \Delta H_{R}
$$

where, from Faraday's law,

$$
\Delta \dot{N}_{H_{2}}=\frac{I}{2 F}
$$

Letting $\dot{Q}=0$ (no external heat transfer), $\dot{W}=I V_{t n}$, yields

$$
V_{t n}=\Delta H_{R} / 2 F
$$

Note that the reaction heat flux of Eq. (16) can also be written in terms of the thermal-neutral voltage as:

$$
q^{\prime \prime}=i\left(V_{N}-V_{t n}\right)
$$

Since the enthalpy of reaction, $\Delta H_{R}$, is strictly a function of temperature (ideal gas approximation), the thermal-neutral voltage is also strictly a function of temperature, independent of cell $A S R$ and gas compositions. The particular values of net cell heat flux at other operating voltages do however depend on cell $A S R$ and gas compositions. The thermal-neutral voltage increases only slightly in magnitude over the typical operating temperature range for solid-oxide cells, from $1.287 \mathrm{~V}$ at $800^{\circ} \mathrm{C}$ to $1.292 \mathrm{~V}$ at $1000^{\circ} \mathrm{C}$. At typical solid-oxide electrolysis cell (SOEC) or stack temperatures, operation at the thermal-neutral voltage yields current densities in the $0.25-1.0 \mathrm{~A} / \mathrm{cm}^{2}$ range, depending on cell performance, which is similar to the current density range that has yielded successful long-term operation in solid-oxide fuel cell (SOFC) stacks.

Operation at or near the thermal-neutral voltage simplifies thermal management of the stack since no significant excess gas flow is required for cooling or heating and component thermal stresses are minimized. In fact, in the electrolysis mode, since oxygen is being produced, there is also no theoretical need for air flow to support the reaction at all. In a large-scale electrolysis plant, the pure oxygen produced by the process could be saved as a valuable commodity. However, there are several good reasons to consider the use of a sweep gas on the oxygen side. First, the use of a sweep gas will minimize the performance degradation associated with any small leakage of hydrogen from the steam/hydrogen side to the oxygen side of the cell. Second, there are serious materials issues associated with the handling of pure oxygen at elevated 
temperatures. Finally, the use of a sweep gas (especially one that does not contain oxygen) on the oxygen side of the electrolysis cell reduces the average mole fraction and partial pressure of oxygen, thereby reducing the open-cell and operating potentials, potentially resulting in higher electrolysis efficiencies. A sweep gas can also be used as a heat transfer fluid, delivering high temperature process heat directly to the stack, allowing high efficiency steady-state operation below the thermal neutral voltage.

There are some additional thermodynamic implications related to the thermal neutral voltage. In particular, electrolyzer operation at or above the thermal neutral voltage negates the argument that is often stated as a motivation for hightemperature electrolysis that a fraction of the total energy requirement can be supplied in the form of heat. In fact, for isothermal operation at voltages greater than thermal neutral, heat rejection is required.

Electrolysis efficiency, $\eta_{e}$, can be defined for HTE, analogous to the definition of fuel cell efficiency [33]. The electrolysis efficiency quantifies the heating value of the hydrogen produced by electrolysis per unit of electrical energy consumed in the stack. Based on this definition,

$$
\eta_{e}=\frac{N_{H_{2}} \Delta H_{R}}{V I}
$$

and since the stack electrical current is directly related to the molar production rate of hydrogen via Faraday's law, the electrolysis efficiency can be expressed strictly in terms of cell operating potentials as:

$$
\eta_{e}=\frac{\Delta H_{R} / 2 F}{V_{o p}}=\frac{V_{t n}}{V_{o p}}
$$

The efficiency for the fuel-cell mode of operation is the inverse of Eq. (22). A fuel utilization factor is often included in the fuel-cell efficiency definition, but it is not needed in the electrolysis definition since no fuel (only steam which can be recycled) is "wasted" at low utilization.

\section{THERMAL REQUIREMENTS FOR SOEC OPERATION}

The analyses presented so far have assumed isothermal electrolyzer operation such that the outlet temperature of the products is the same as the inlet temperature of the reactants. For operating voltages between the open-cell potential and thermal neutral, isothermal operation requires net heat addition during the electrolysis process. For operating voltages above thermal neutral, net heat rejection is required to maintain isothermal operation. The enthalpy change for the electrolysis process under isothermal conditions is, by definition, the "enthalpy of reaction," $\Delta H_{R}$. The enthalpy of reaction for steam reduction is a weak function of temperature, with a numerical value very close to the low heating value of hydrogen over a wide range of temperatures, as shown in Fig. 6. The magnitude of the heat transfer required to achieve isothermal operation, $\dot{Q}_{T}(T)$, can be calculated directly from the following form of the first law:

$$
\dot{Q}_{T}(T)=\Delta \dot{N}_{H_{2}} \Delta H_{R}(T)-I V_{o p}
$$

and since the hydrogen production rate, $\Delta \dot{N}_{H_{2}}$ is equal to I/2F, and the thermal neutral voltage, $V_{t n}=\Delta H_{R}(T) / 2 F$,

$$
\dot{Q}_{T}(T)=I\left(V_{t n}-V_{o p}\right)
$$

Note that this result predicts positive heat transfer to the electrolyzer for operating voltages less than thermal neutral and negative heat transfer (i.e., heat rejection from the electrolyzer) for operating voltages greater than thermal neutral. Since there is no sensible enthalpy change, this result is valid for all isothermal cases, even if excess reactants and/or inert gases are present.

Eq. (24) can also be used to show that the maximum isothermal heat addition operating point corresponds to an operating voltage equal to the average of the open-cell potential and the thermal neutral voltage. Accordingly, the maximum isothermal heat addition is given by:

$$
\dot{Q}_{\max }(T)=I\left(\frac{V_{t n}-V_{N}}{2}\right)
$$

where $V_{N}$ is the open-cell potential. The total stack current, $I$, at any operating voltage is dependent on the stack $A S R$ value, which is typically temperature-dependent.

Actual high-temperature electrolysis processes will generally not operate isothermally unless the operating voltage is very close to the thermal neutral voltage. For non-isothermal cases, the first law for electrolysis process must be written as:

$$
\begin{aligned}
\dot{Q}-W=\sum_{P} \dot{N}_{i}\left[\Delta H_{f_{i}}^{o}+H_{i}\left(T_{P}\right)-H_{i}^{o}\right] \\
\quad-\sum_{R} \dot{N}_{i}\left[\Delta H_{f_{i}}^{o}+H_{i}\left(T_{P}\right)-H_{i}^{o}\right]
\end{aligned}
$$

In this form, all reacting and non-reacting species included in the inlet and outlet streams can be accounted for, including inert gases, inlet hydrogen (introduced to maintain reducing conditions on the steam/hydrogen electrode), and any excess unreacted steam. In general, determination of the outlet temperature from Eq. (26) is an iterative process [34]. The heat transferred during the process must first be specified (e.g., zero for the adiabatic case). The temperature-dependent enthalpy values of all species must be taken into account. The solution procedure begins with specification of the cathode-side inlet flow rates of steam, hydrogen, and any inert carrier gas such as nitrogen (if applicable). The inlet flow rate of the sweep gas (e.g., air or steam) on the anode side must also be specified. Specification of these flow rates allows for the determination of the inlet mole fractions of steam, hydrogen, and oxygen that appear in the Nernst equation. The steam mole fraction is expressed in terms of the hydrogen mole fraction as $1-y_{H 2}-y_{N 2}$. The desired current density and active cell area are then specified, yielding the total operating current. The corresponding hydrogen production rate is obtained from Faraday's law. 
Once the per-cell hydrogen production rate is known, the outlet flow rates of hydrogen and steam on the cathode side and oxygen on the anode side can be determined. The flow rates of any inert gases, the anode-side sweep gas, and any excess steam or hydrogen are the same at the inlet and the outlet. Once all these flow rates are known, the summations in Eq. (26) can be evaluated. The product summation must be evaluated initially at a guessed value of the product temperature, $T_{P}$.

The operating voltage corresponding to the specified current density is obtained from

$$
V_{o p}=\bar{V}_{N}+i \times A S R,
$$

where the stack area-specific resistance, $A S R$, must be estimated and specified as a function of temperature. To account for the variation in temperature and composition across an operating cell, the mean Nernst potential, $\bar{V}_{N}$, can be obtained from an integrated version of the Nernst equation:

$$
\begin{aligned}
\bar{V}_{N}= & \frac{1}{2 F\left(T_{P}-T_{R}\right)\left(y_{o, O_{2}, A}-y_{i, O_{2}, A}\right)\left(y_{o, H_{2}, C}-y_{i, H_{2}, C}\right)} \times \\
& \iiint_{R}^{P} \Delta G_{R}(T)+R_{u} T \ln \left(\frac{1-y_{H_{2}}-y_{N_{2}}}{y_{H_{2}} y_{O_{2}}^{1 / 2}}\right) d y_{H_{2}} d y_{O_{2}} d T
\end{aligned}
$$

where $y_{i, O_{2}, A}$ is the anode-side inlet mole fraction of oxygen, etc. Note that the upper limit of integration on the temperature integral is initially unknown. Once the $A S R$ and the mean Nernst potential are known, the operating voltage is obtained from Eq. (27) and the electrical work term in Eq. (26) is obtained from $\dot{W}=-V_{o p} I$. An algorithm then must be developed to iteratively solve for the product temperature, $T_{P}$, in order to satisfy Eq. (26).

The procedure described above was formulated as an integral electrolyzer model [34] that was used for direct incorporation into large-scale system models [e.g., 15, 35]. Actual electrolyzers will generally operate at conditions that are neither isothermal, nor adiabatic. These two cases represent limits. For optimal performance, isothermal operation at an operating voltage below thermal neutral is desirable. In this case, some of the electrolysis energy is indeed supplied in the form of heat. One way to supply the required heat directly to the stack is through the use of a heated sweep gas. This strategy is just the opposite of the situation encountered in the fuel cell mode in which excess air is used for cell cooling.

\section{ELECTROLYSIS CELL DESIGNS AND STACK CONFIGURATIONS}

Several basic cell designs have been developed for SOFC applications including electrolyte-supported, electrodesupported, and porous ceramic or metal substrate-supported cells. A full discussion of these various cell designs and the various fabrication techniques is beyond the scope of this paper. Common cell characteristics include a dense gas-tight (hermetic) electrolyte layer, with porous electrodes on either side. In an electrolyte-supported cell, the electrolyte layer is thicker than either of the electrodes and must have sufficient mechanical strength to withstand any stresses. However, as a result of the relatively thick electrolyte, ionic resistance across the electrolyte is large for this design. The best performing SOFC cells at present are the anode-supported cells in which the mechanical strength is provided by a thick $(\sim 1.0-1.5 \mathrm{~mm})$ layer of anode (usually nickel-YSZ cermet) material (e.g., [36]). Thin electrolyte and cathode layers are deposited on the anode material by screen printing or other techniques. This design has exhibited very high performance in SOFC tests. Some researchers have suggested that the best performance for the electrolysis mode of operation could be obtained using airside (e.g., LSM) electrode-supported cells [37]. In the SOEC mode, air-electrode-supported cells should exhibit a lower concentration polarization than steam-hydrogen-electrode supported cells, due to the direction of steam and oxygen diffusion in the two modes. A wealth of information on materials, configurations, and designs of solid-oxide electrochemical systems is available in [38].

A research program on high temperature electrolysis (HTE) at the Idaho National Laboratory (INL) has demonstrated the feasibility of HTE for efficient hydrogen production from steam. The majority of the electrolysis stack testing that has been performed at INL to date has been with planar stacks fabricated by Ceramatec, Inc. of Salt Lake City, UT. The planar stack configuration yields the highest volumetric energy density for HTE stacks, but planar stacks are more difficult to seal, which is especially important in the electrolysis mode. An exploded view of the internal components of one of these stacks is shown in Fig. 9. The cells have an active area of $64 \mathrm{~cm}^{2}$. The stacks are designed to operate in cross flow, with the steam / hydrogen gas mixture flowing from front to back in the figure and air flowing from right to left. Air flow enters at the rear though an air inlet manifold and exits at the front directly into the furnace. The power lead attachment tabs, integral with the upper and lower

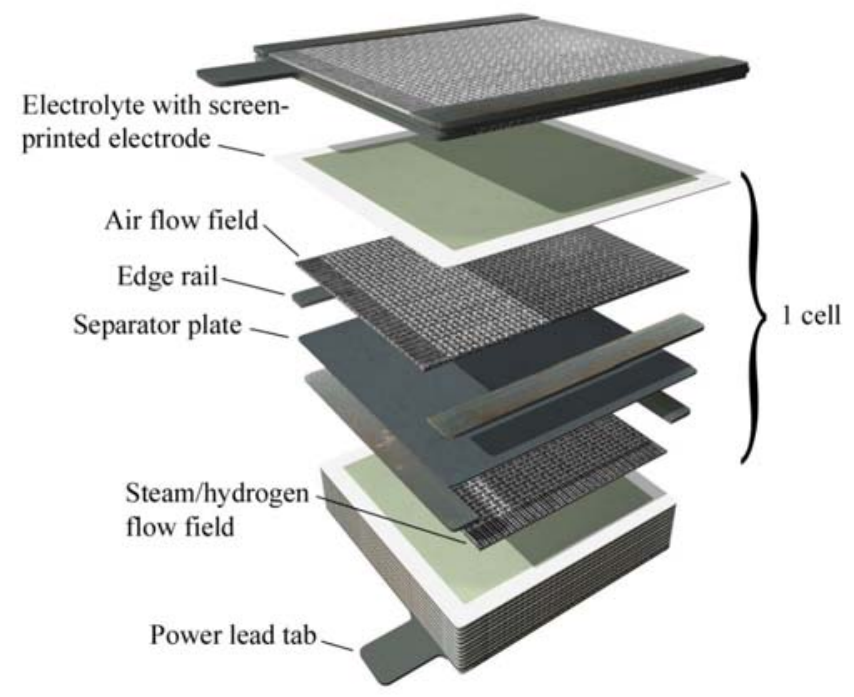

Figure 9. Exploded view of a planar SOEC stack. 
interconnect plates are also visible in Fig. 9. Stack operating voltages were measured using wires that were directly spotwelded onto these tabs. The interconnect plates are fabricated from ferritic stainless steel. Each interconnect includes an impermeable separator plate $(\sim 0.46 \mathrm{~mm}$ thick) with edge rails and two corrugated "flow fields," one on the air side and one on the steam/hydrogen side. The height of the flow channel formed by the edge rails and flow fields is $1.0 \mathrm{~mm}$. Each flow field includes 32 perforated flow channels across its width to provide uniform gas-flow distribution. The steam/ hydrogen flow fields are fabricated from nickel foil. The air-side flow fields are ferritic stainless steel. The interconnect plates and flow fields also serve as electrical conductors and current distributors. To improve performance, the air-side separator plates and flow field surfaces are pre-treated to form a rareearth stable conductive oxide scale. A perovskite rare-earth coating is also applied as a bond layer to the separator-plate oxide scale by either screen printing or plasma spraying. On the steam/hydrogen side of the separator plate, a thin $(\sim 10 \mu \mathrm{m})$ nickel metal coating is applied as a bond layer.

The stack electrolytes are scandia-stabilized zirconia, about $140 \mu \mathrm{m}$ thick. The air-side electrodes (anode in the electrolysis mode), are a strontium-doped manganite. The electrodes are graded, with an inner layer of manganite/ zirconia $(\sim 13 \mu \mathrm{m})$ immediately adjacent to the electrolyte, a middle layer of pure manganite $(\sim 18 \mu \mathrm{m})$, and an outer bond layer of cobaltite. The steam/ hydrogen electrodes (cathode in the electrolysis mode) are also graded, with a nickel-zirconia cermet layer $(\sim 13 \mu \mathrm{m})$ immediately adjacent to the electrolyte and a pure nickel outer layer $(\sim 10 \mu \mathrm{m})$.

Planar stacks can also be assembled using electrodesupported cells. Advanced technology SOFC stacks based on anode-supported cell technology have been developed by several manufacturers under the Solid-State Energy Conversion Alliance (SECA) [39] program. For example, Versa Power Systems has developed anode-supported planar cells with dimensions as large as $33 \times 33 \mathrm{~cm}$ [40]. Their stacks are internally manifolded, as shown in Fig. 10.
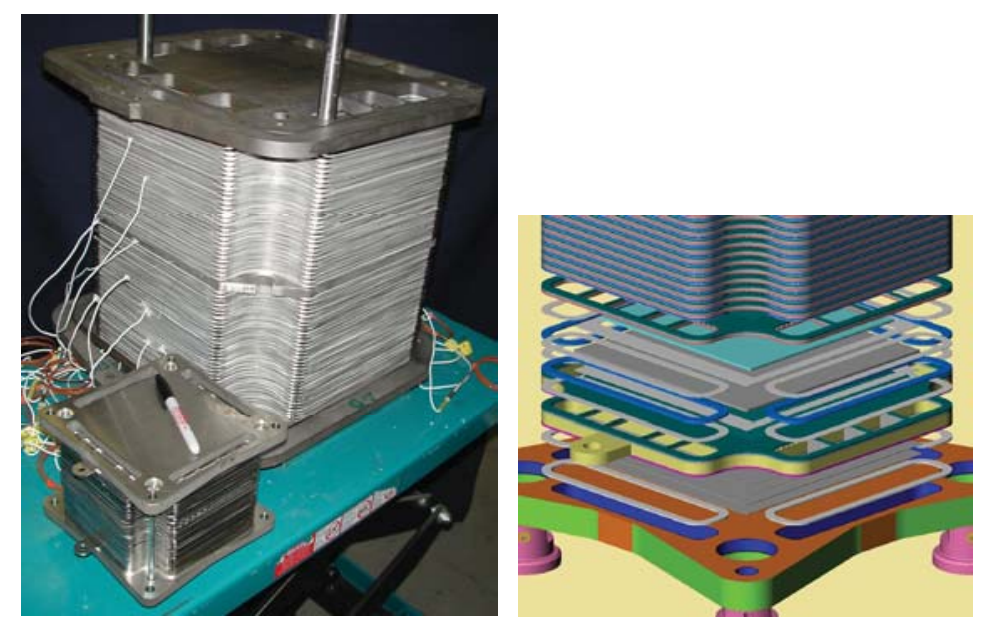

Figure 10. Internally manifolded planar stack with anode-supported cells, developed by Versa Power.

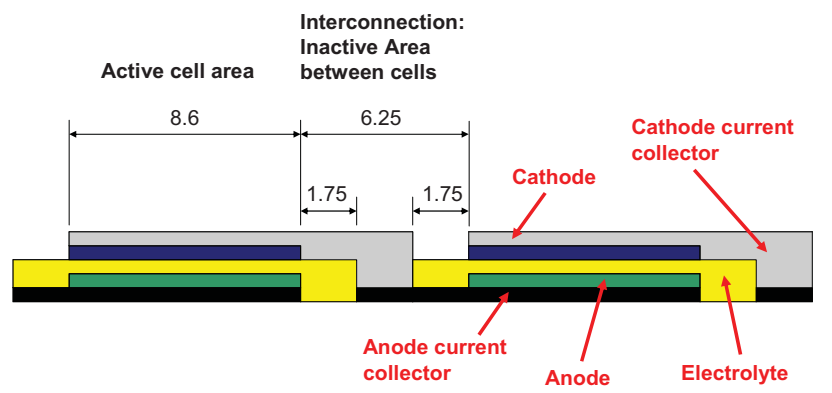

(a)

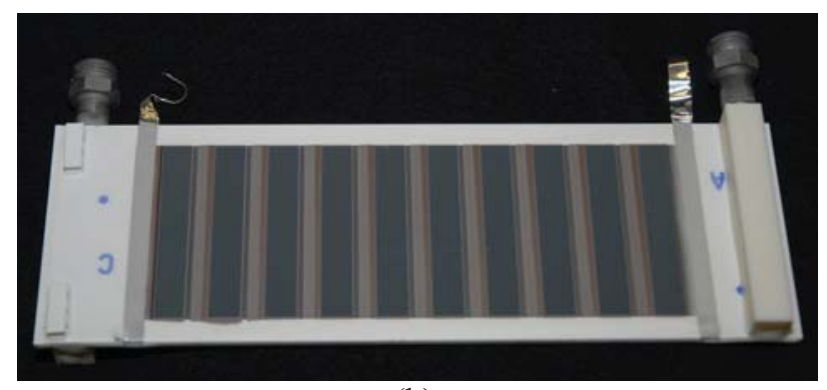

(b)

Figure 11. Rolls Royce integrated planar cells; (a) schematic of cells layers, (b) photograph of IP-SOFC tube.

Additional cell and stack configurations are under development for SOFC applications, including tubular and integrated planar designs. INL participated in a CRADA with Rolls Royce Fuel Cell Systems (RRFCS) to evaluate the performance of their cells operating in the electrolysis mode. The RRFCS cells utilize a segmented-in-series integrated planar (IP-SOFC) design [41] in which thin electrode and electrolyte layers are screen-printed on the surface of a flattened ceramic tube, as shown in Fig. 11. Figure 11(a) is a schematic representation of the electrochemical layers. Figure $11(\mathrm{~b})$ is a photograph of one of an IP-SOFC tube that was tested at INL in the SOEC mode.

\section{HIGH-TEMPERATURE ELECTROLYSIS EXPERIMENTS}

\section{Small-scale tests}

Results of initial single (button) cell HTE tests completed at the INL were documented in detail in reference [42]. Button cell tests are useful for basic performance characterization of electrode and electrolyte materials and of different cell designs. Polarization curves for several representative DC potential sweeps are presented in Fig. 12(a). Both the applied cell potentials and the corresponding power densities are plotted in the figure as a function of cell current density. Positive current densities indicate fuel cell mode of operation and negative current densities indicate electrolysis mode. Measured cell potential values at zero current density agreed very closely with theoretical values. The Vi curves for the sweeps acquired at $800^{\circ} \mathrm{C}$ (sweeps 1,3 , and 5) have a steeper slope than those obtained at $850^{\circ} \mathrm{C}$, due primarily to the lower electrolyte ionic conductivity at the lower temperature. The continuous nature of the Vi curves across the zero-current-density (open-circuit) 


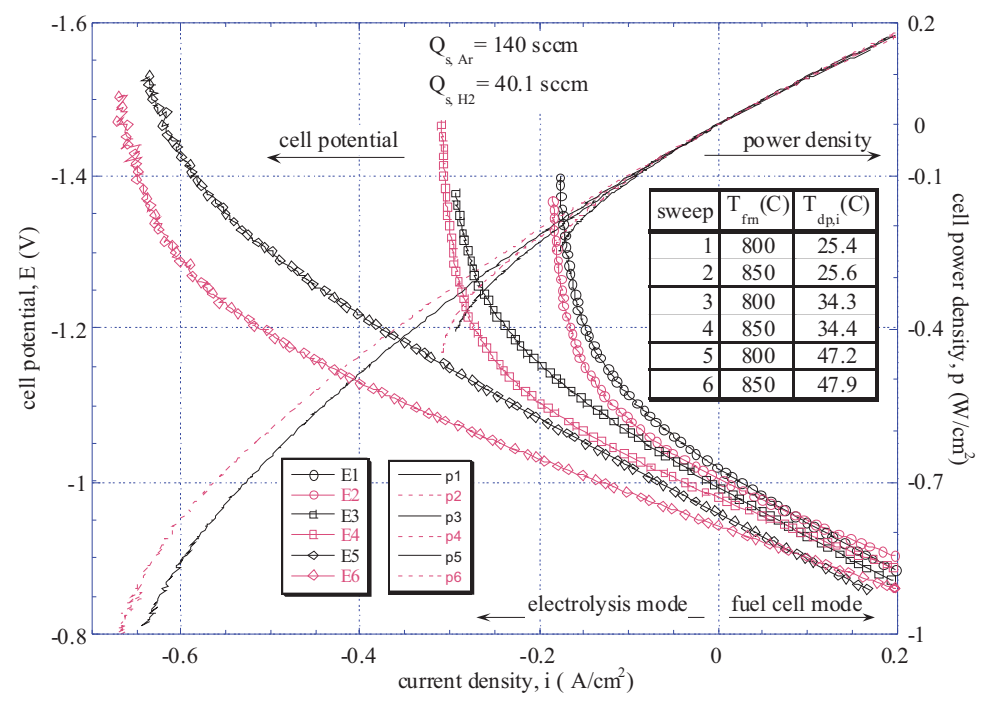

(a)

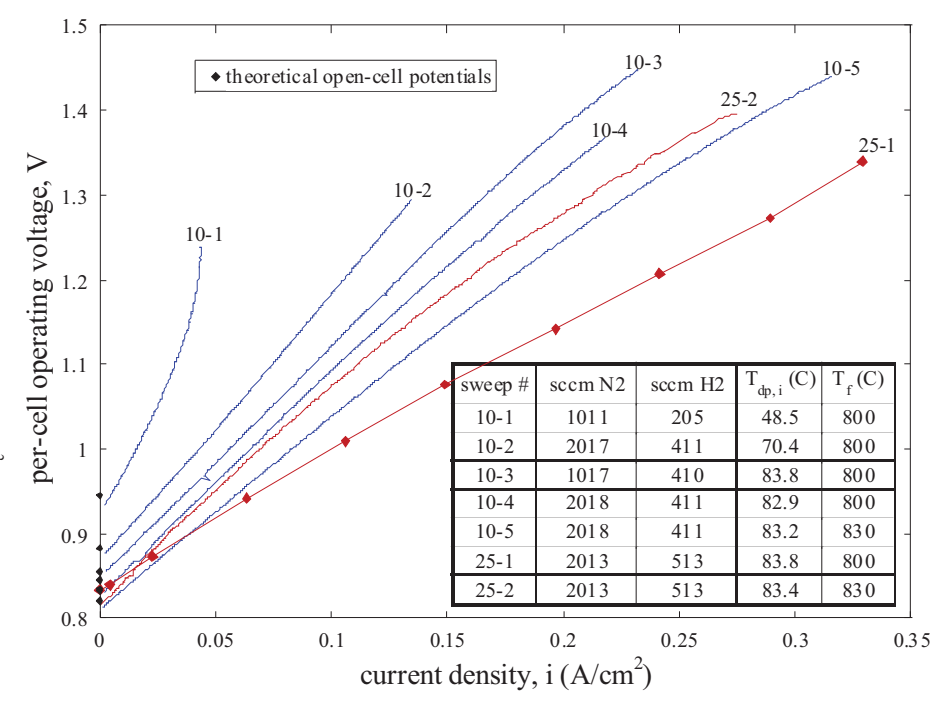

(b)

Figure 12. SOEC polarization curves; (a) button cell, (b) planar stack.

point provides no indication of significant activation overpotential for these electrolyte-supported cells. In the electrolysis mode, the voltage data vary linearly with current density up to a value that depends on the inlet steam content. For low inlet dewpoint values (sweeps 1 and 2), the voltage begins to increase rapidly at relatively low values of current density $\left(\sim-0.15 \mathrm{~A} / \mathrm{cm}^{2}\right)$, due to steam starvation. For higher inlet dewpoints, the steam starvation effect occurs at higher current densities. The single-cell results demonstrated the feasibility of HTE for hydrogen production linear operation from the fuel-cell to the electrolysis mode.

Results of initial short-stack HTE tests performed at INL were provided in references [10] and [43]. A good summary of our experience is provided by the results plotted in Fig. 12(b), from [10]. Results of several representative sweeps are shown in the form of polarization curves, representing per-cell operating voltage versus current density. Test conditions for each of the seven sweeps are tabulated in the figure. Five of the sweeps were obtained from a 10-cell stack (sweeps 10-1 through 10-5) and two were obtained from a 25-cell stack (25-1 and 25-2). Theoretical open-cell potential values are shown in the figure for each sweep using a single data point at zero current density. Note that the measured open-cell potentials are in excellent agreement with the theoretical values for each sweep. Sweep 10-1 was performed with a relatively low inlet steam flow rate, corresponding to the low inlet dewpoint value of $48.5^{\circ} \mathrm{C}$ and relatively low nitrogen and hydrogen flow rates. This sweep has a relatively high slope on i-V coordinates, indicating a relatively high $A S R$. This sweep also clearly shows the effects of steam starvation; the slope of the $i-V$ curve increases dramatically as the current density is increased. The outlet dewpoint temperature corresponding to the highest current density shown in this figure was only $4^{\circ} \mathrm{C}$ for this sweep. Sweep 10-2 was performed at an intermediate steam concentration, with an inlet dewpoint temperature of $70^{\circ} \mathrm{C}$.
This sweep exhibits nearly linear behavior over the range of current densities shown, with a much smaller slope than sweep 10-1. Sweeps 10-3 and 10-4 are nearly linear at low current densities, then slightly concave-down at higher current densities. Sweep 10-5 has a shallower slope than the others, consistent with the higher operating temperature of $830^{\circ} \mathrm{C}$. Sweep 25-1 was performed in a stepwise fashion, rather than as a continuous sweep. This was done in order to ensure sufficient time for the measured internal stack temperatures to achieve steady-state values at each operating voltage. Note that the slope of this sweep is small, indicating relatively low $A S R$ $\left(\sim 1.5 \Omega \cdot \mathrm{cm}^{2}\right)$. This sweep was performed at the beginning of a 1000-hour long-duration 25-cell stack test. Sweep 25-2 was acquired at the end of the long-duration test. The stack operating temperature was increased form $800^{\circ} \mathrm{C}$ to $830^{\circ} \mathrm{C}$ part way through the test. Note that the slope of sweep 25-2 is higher than that of sweep 25-1, despite the higher temperature, due to performance degradation over 1000 hours of operation.

\section{Large-Scale Demonstrations}

One of the objectives of the INL HTE program is technology scale-up and demonstration. To this end, the INL developed a $15 \mathrm{~kW}$ HTE test facility, termed the Integrated Laboratory Scale (ILS) facility. An overview photograph of the ILS is provided in Fig. 13. Details of the design and initial operation of this facility are documented in references [44 - 46]. A condensed description of the facility will be provided here. The ILS includes three electrolysis modules, each consisting of four stacks of 60 cells, yielding 240 cells per module and 720 cells total. The cells were supplied by Ceramatec and are similar to those discussed earlier. Each electrolysis module utilizes an independent support system supplying electrical power for electrolysis, a feedstock gas mixture of hydrogen and steam (and sometimes nitrogen), a sweep gas, and appropriate exhaust handling. Each module includes a controlled inlet flow 


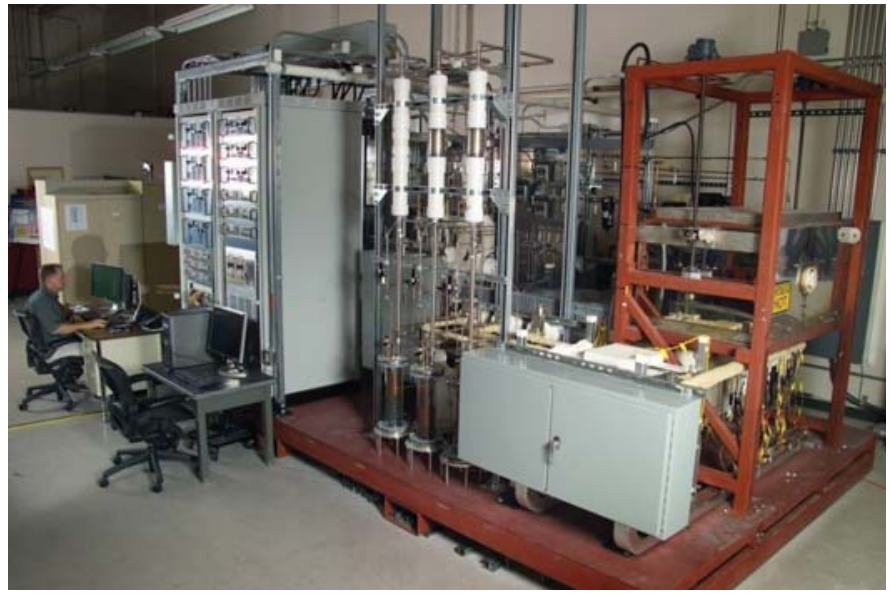

Figure 13. $15 \mathrm{~kW}$ Integrated Laboratory Scale HTE test facility at INL.

of deionized water, a steam generator, a controlled inlet flow of hydrogen, a superheater, inlet and outlet dewpoint measurement stations, a condenser for residual steam, and a hydrogen vent. All three modules were located within a single hot zone. Heat recuperation and hydrogen product recycle were also incorporated into the facility

An exploded view of one of the ILS module assemblies including the recuperative heat exchanger, base manifold unit, and four-stack electrolysis unit is presented in Fig. 14. For each four-stack electrolysis module, there were two heat exchangers and one base manifold unit. Each base manifold unit has nine flow tubes entering or exiting at its top and only four flow tubes entering or exiting at the bottom of the unit and at the bottom of the heat exchangers, thereby reducing the

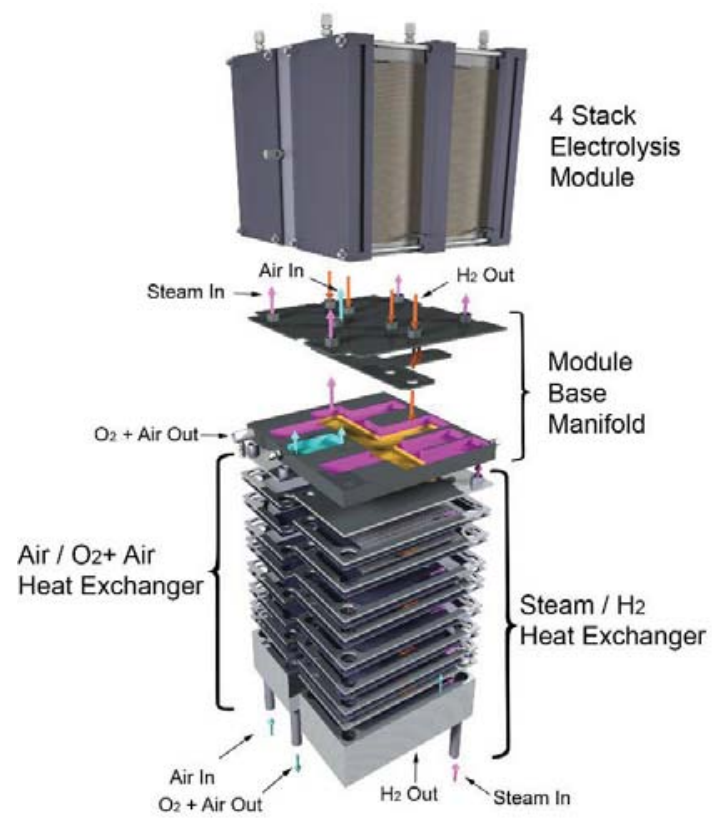

Figure 14. Exploded view of single ILS module, showing heat exchanger, base manifold, and four-stack electrolysis unit. number of tube penetrations passing through the hot zone base plate from nine to just four. This feature also reduces the thermal load on the hot zone base plate. An internally manifolded plate-fin design concept was selected for the heat recuperator. This design provides configuration flexibility in terms of selecting the number of flow elements per pass and the total number of passes in order to satisfy the heat transfer and pressure drop requirements. Excellent heat exchanger performance can be achieved with this design. This design can also accommodate multiple fluids in a single unit. More details of the design of the recuperative heat exchangers are provided in [47].

Fig. 15 shows a cut-away design rendering of the three ILS electrolysis modules with their base manifolds and heat exchangers beneath. This illustration also shows the instrumentation wires for intermediate voltage and temperature readings. Each module is instrumented with twelve 1/16" sheathed thermocouples for monitoring gas temperatures in the electrolysis module manifolds and in the base manifold. These thermocouples are attached to the manifolds using compression fittings. There are also twelve miniature 0.020 " diameter inconel-sheathed type- $\mathrm{K}$ thermocouples per module that are used for monitoring internal stack temperatures. Access to the internal region of the stacks is provided via the air outlet faces. The internal thermocouples are inserted into the small exit air flow channels. Similarly, seven intermediate voltage tap wires per module are inserted into the air flow channels of the four stacks.

Two compression bars are shown across the top of each module in Fig. 15. These bars are used to maintain compression on all of the stacks during operation in order to minimize electrical contact resistance between the cells, flow fields, and interconnects. The bars are held in compression via spring-loaded tie-downs located outside of the hot zone under the base plate.

Note that the heat exchangers are partially imbedded in the insulation thickness. The top portion of each heat exchanger is exposed to the hot zone radiant environment,

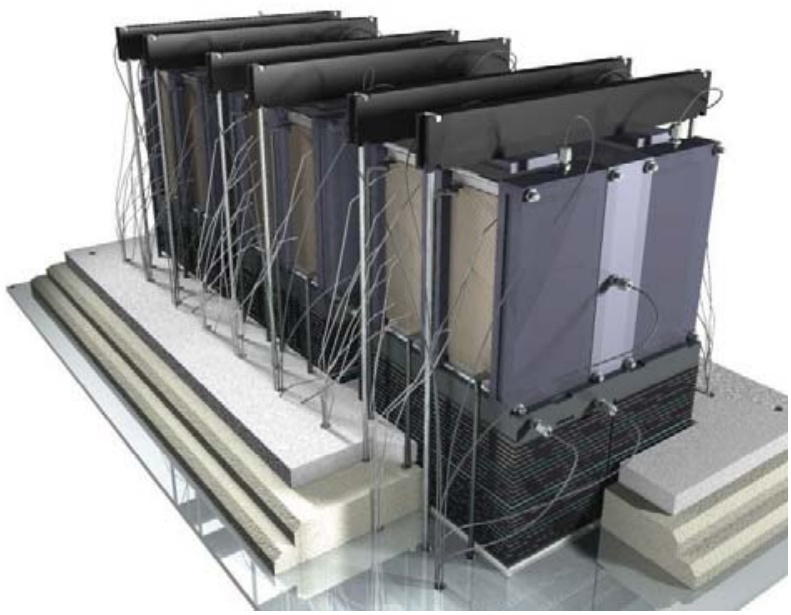

Figure 15. Design rendering of the ILS modules mounted in hot zone. 


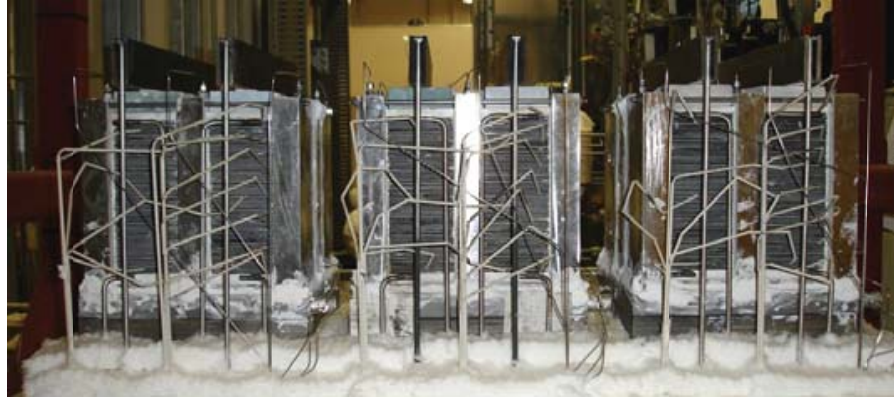

Figure 16. ILS hot zone with three HTE modules installed.

which helps to insure that the inlet gas streams achieve the desired electrolyzer operating temperature prior to entering the stacks. The temperature at the bottom of each heat exchanger will be close to the inlet stream temperature, minimizing the thermal load on the hot zone base plate in the vicinity of the tubing penetrations. A photograph of the three ILS electrolysis modules installed in the hot zone is shown in Fig. 16.

Initial performance of the ILS system is documented in detail in references [48, 49]. Peak electrolysis power consumption and hydrogen production rates were $18 \mathrm{~kW}$ and $5.7 \mathrm{Nm}^{3} / \mathrm{hr}$, respectively, achieved at about 17 hours of elapsed test time. Performance degradation was relatively rapid, however, due to a combination of effects, including balance of plant issues. Initial $A S R$ values were near $1.5 \mathrm{Ohm} \cdot \mathrm{cm}^{2}$, but these increased dramatically over the first $700 \mathrm{hrs}$ of operation. Despite the problems with the ILS, the test successfully demonstrated large-scale hydrogen production with heat recuperation and hydrogen recycle.

\section{HEAT AND MASS TRANSFER IN SOECS}

Since this paper has been prepared for the International Heat Transfer Conference, it is appropriate to discuss the heat and mass transfer phenomena that occur in solid-oxide cells. A schematic depiction of these phenomena is presented in Fig. 17. These cells operate at relatively high temperature, around 800 $900^{\circ} \mathrm{C}$, so radiation heat transfer can be important. In a stack configuration, radiant exchange between the outer surfaces of the stack and the surrounding hot zone surfaces is important in determining the temperature distribution within the stack. Consideration of the effects of participating gases such as steam and carbon dioxide (which may be present in an SOEC for the case of co-electrolysis) within the stack can also be important [50].

Conduction and convection heat transfer occurs in the gas flow channels within a stack. Since electrical continuity must be maintained between the separator plates and the electrodes, these flow channels typically consist of multiple small parallel flow channels, with numerous electrical contact points on both the separator plate and the electrode. Due to the small flow channel characteristic dimensions $(\sim 1 \mathrm{~mm})$, Reynolds numbers are typically quite low, so the flows are usually laminar. However, the transport situation is complicated in the flow channels by the fact that the gas composition changes in the flow direction due to the electrochemical reactions (shown in Fig. 17) occurring in the triple-phase boundary region near the electrode/electrolyte interface. On the steam / hydrogen side, in the electrolysis mode, the inlet flow (at temperature $T_{i}$ and pressure $\mathrm{P}$ ) is mostly steam, with some hydrogen (required to maintain reducing conditions at the nickel cermet electrode) and possibly an inert carrier gas such as nitrogen. The mass flow rate on this side of the cell decreases in the flow direction due to the electrochemical reduction of steam. The volume flow rate on the steam / hydrogen side is constant, however, so the bulk flow velocity is constant.

The electrodes are porous, with a graded porosity that is finest near the electrode-electrolyte interface. Counterdiffusion of steam and hydrogen occurs in the porous cathode. Oxygen ions are transported through the electrolyte material. On the opposite side of the cell, oxygen is evolved due to recombination of electrons with oxygen ions. Therefore the flow rate of sweep gas (usually air) on the anode side of the cell increases in a fashion similar to a transpiration flow. Recognizing all of these phenomena, determination of a steadystate temperature distribution in a cell/stack must include the

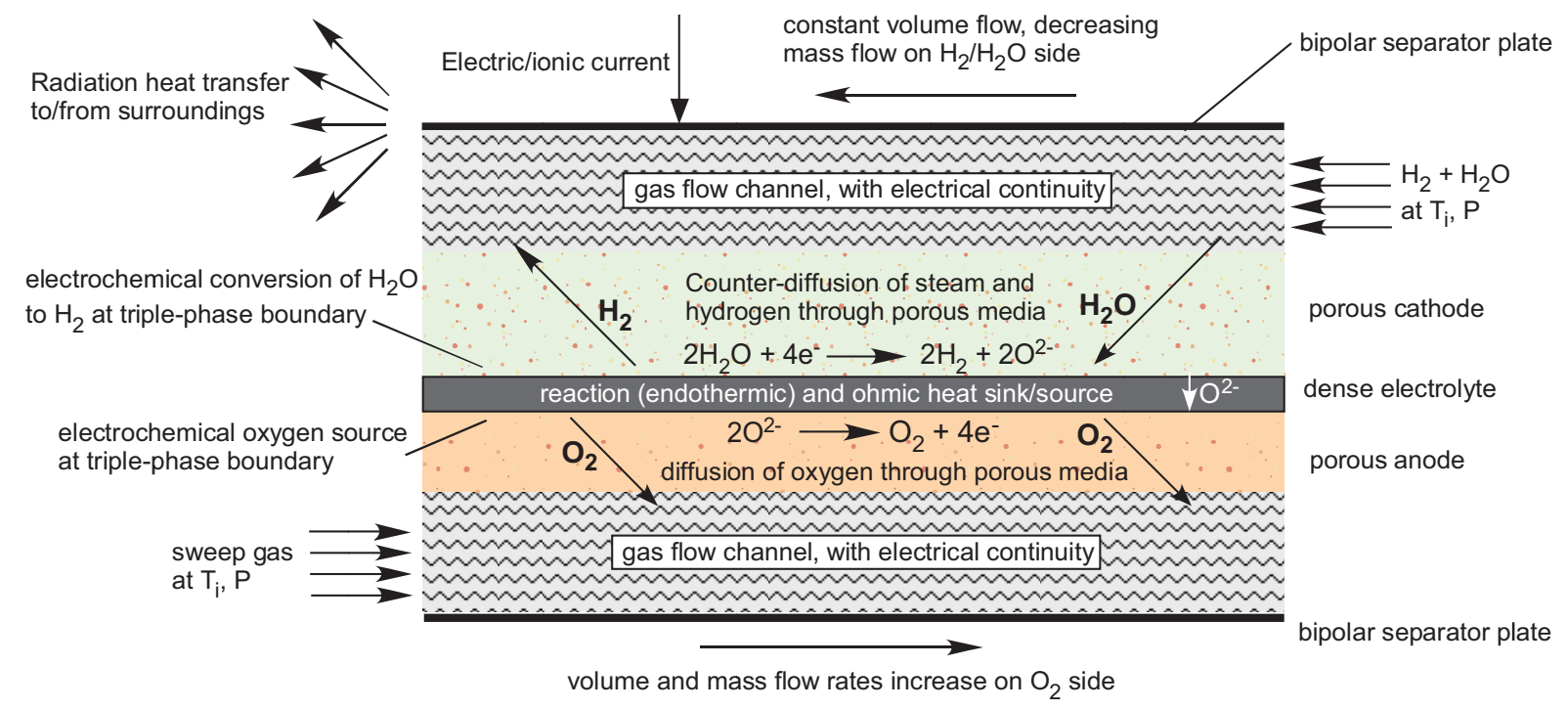

Figure 17. Transport and electrochemical phenomena in solid-oxide electrolysis cells. 
usual conservation of mass, momentum energy, plus electrochemistry and electric field conservation. Reaction kinetics must also be modeled, typically using a Butler-Volmer model for activation.

\section{COMPUTATIONAL ANALYSIS OF SOECS}

Significant effort has been spent in recent years in the development of numerical modeling methods for detailed thermal and electrochemical analysis of solid-oxide fuel cells. Relatively little work as been completed for SOEC modeling. Fluent Inc. was funded by the US Department of Energy National Energy Technology Laboratory (DOE-NETL) to develop a solid-oxide fuel cell (SOFC) module [51] for coupling to the core mass, momentum, energy, and species conservation and transport features of the FLUENT computational fluid dynamics (CFD) code [52]. The SOFC module adds the electrochemical reactions, loss mechanisms and computation of the electric field throughout the cell. It also adds species and energy sources and sinks arising from the electrochemistry at the electrode-electrolyte interfaces. Under a cooperative effort between INL and Fluent, Inc., the FLUENT SOFC user-defined subroutine was modified to allow for operation in the SOEC mode. Model results provide detailed profiles of temperature, Nernst potential, operating potential, anode-side gas composition, cathode-side gas composition, current density and hydrogen production over a range of stack operating conditions.

\section{Numerical Model of a Planar SOEC Stack}

Complete details of a FLUENT electrolysis stack model developed at INL for analysis of a planar stack configuration are provided in [53]. The numerical model developed for this analysis was based on the geometry of a single solid-oxide electrolysis cell (SOEC) taken from a planar stack similar to the stack described in detail in [43]. The numerical domain extends from the center plane of one separator plate to the center plane of the next separator plate. Symmetry boundaries are applied at the top and bottom of the model.

The flow channels are the regions in the stack between the separator plate, the edge rails and the electrodes in which the corrugated/perforated "flow fields" are located. In the FLUENT model, the flow channels were specified as highporosity porous-media regions with metallic nickel as the solid material on the steam/hydrogen side and ferritic stainless steel on the air side. The flow channels have anisotropic permeability, much higher in the primary flow direction than in the cross flow directions. The height of the flow channel is set by the thickness of the edge rails, $1.019 \mathrm{~mm}$.

The FLUENT solid-oxide fuel cell (SOFC) module treats the electrolyte as a 2-D planar element with the properties of yttria-stabilized zirconia (YSZ). Therefore the electrolyte in the model has geometrical thickness of zero (the newer version of the FLUENT SOFC module allows for a 3-D electrolyte). On either side of the electrolyte are the electrodes which are created with 3-D elements. Therefore, the electrolyte/electrode assembly in this model was only as thick as the two electrodes. The top separator plate and edge rails are identical to those on the bottom, but the edge rails are oriented perpendicular to the bottom edge rails to allow for the cross-flow arrangement. The bottom separator plate in the FLUENT model serves as the electrical ground and the top separator plate serves as the current source.

Additional parameters specified in the numerical model include the electrode exchange current densities and several gap electrical contact resistances. These quantities were determined empirically by comparing FLUENT predictions with stack performance data. The FLUENT model uses the electrode exchange current densities to quantify the magnitude of the activation overpotentials via a Butler-Volmer equation [51]. Results of the numerical model have been compared to experimental results obtained from a ten-cell planar stack.

\section{Representative Computational Results}

Representative results obtained from the integral electrolyzer model [34] for an adiabatic case are presented in Fig. 18, along with results obtained from FLUENT. Fig. 18 shows predicted voltage-current characteristics and predicted gas outlet temperatures. The integral model predicts somewhat higher operating voltages compared to the FLUENT results. This makes the model conservative since higher operating voltages correspond to lower electrolysis efficiencies. The disparity can be explained by noting that the CFD model can more accurately account for the variation in local Nernst potential and local current density associated with the crossflow geometry of the planar stack. Note that, for an operating voltage near the thermal minimum $(\sim 1.06 \mathrm{~V})$, both models predict outlet temperatures for this particular adiabatic case that are about $30^{\circ} \mathrm{C}$ lower than the inlet temperatures. Per-cell gas flow rates for this case were based on the flow rates used in planar HTE stack tests [43]. The integral model also predicts the correct value of the thermal neutral voltage for $800^{\circ} \mathrm{C}$, $1.287 \mathrm{~V}$. At this operating voltage, the outlet temperatures are equal to the inlet temperatures under adiabatic conditions.

Results obtained from FLUENT were also compared to experimental results. One set of representative results is shown in Fig. 19. The results shown correspond to sweep 25-1 of Fig. 12(b). This sweep was performed in a stepwise fashion in order to allow sufficient time at each operating condition for steady-state thermal conditions to be achieved in the stack. The figure shows experimentally measured voltage-current characteristics and internal stack temperatures obtained during a DC potential sweep, along with FLUENT predictions. The FLUENT model included empirical values for internal stack contact resistances, scaled to match the measured voltagecurrent values of sweep 25-1. This scaling is necessary because it is not possible to predict these contact resistance values from first principles. Corresponding predicted and measured internal stack temperatures are shown in Fig. 19(b). The experimental internal stack temperatures were obtained from miniature thermocouples that were inserted into selected air-flow channels. The comparison between the experimentally obtained stack internal temperatures and the FLUENT mean electrolyte temperature is quite good, and serve to validate the 


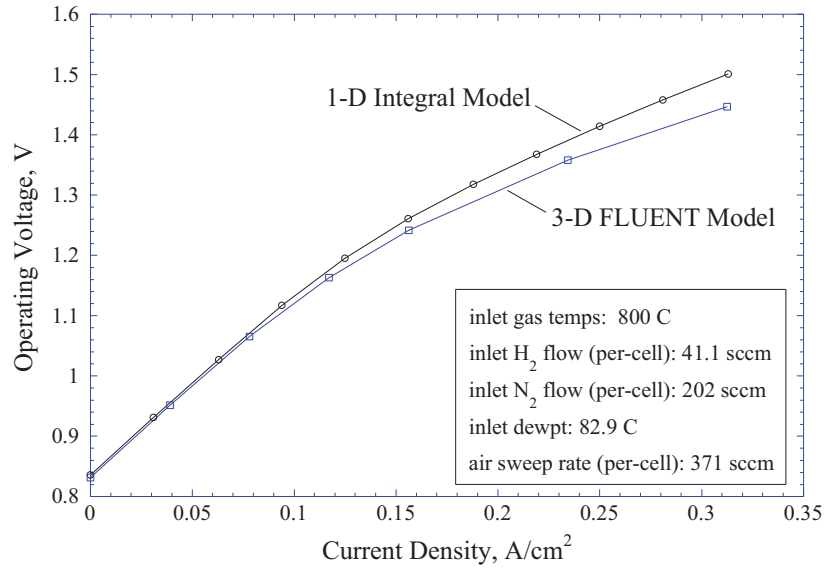

(a)

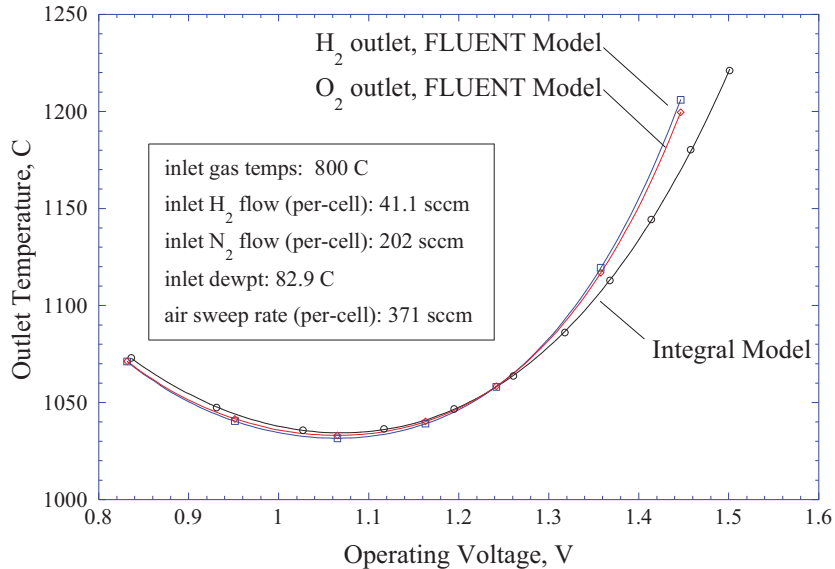

(b)

Figure 18. Predicted operating voltage and gas outlet temperatures for adiabatic electrolyzer operation; comparison of integral model with full 3-D FLUENT simulation.

numerical methods and models used.

Detailed CFD analyses also provide a means of visualizing details of temperature and current density distributions within operating cells and stacks, as shown in Figs. 20 and 21. In these figures, the steam/hydrogen flow is from top to bottom and the air flow is from left to right. Fig. 20 shows electrolyte temperature contour plots for total cell current values of 10, 15, and 30 amps. These values of current correspond to operating voltage regimes near the minimum electrolyte temperature (10 amps), near thermal neutral voltage (15 amps), and in the region dominated by ohmic heating $(30 \mathrm{amps})$. The radiant boundary condition at $1103 \mathrm{~K}$ tends to hold the outside of the model at a higher temperature for the 10-amp case (Fig. 20(a)) while the endothermic heat requirement maintains the center of the electrolyte at a lower temperature. Minimum and maximum temperatures for this case are $1091 \mathrm{~K}$ and $1100 \mathrm{~K}$ respectively. The center Fig. 20(b) shows a temperature difference across the electrolyte of only one degree $\mathrm{K}$, with values very near $1103 \mathrm{~K}$; this current density is very near the thermal neutral voltage. Fig. 20(c) shows that ohmic heating in the electrolyte is dominant and that the thermal boundary condition keeps the edges cooler than the inside. Minimum and maximum temperatures are $1139 \mathrm{~K}$ and $1197 \mathrm{~K}$, respectively, for this case.

Contour plots of local current density on the electrolyte are shown in Fig. 21 for 10, 15, and 30 amps. Mean current densities for these three cases are: $0.156,0.234$, and 0.469 $\mathrm{A} / \mathrm{cm}^{2}$. These plots correlate directly with local hydrogen production rates. Since FLUENT is being run in electrolysis mode, the current density values are all negative and hence the blue values have the largest magnitudes. Highest current density magnitudes occur near the steam hydrogen inlet (the top of the figures). This corresponds to the location of the greatest steam concentration. The orange areas show where the current density is lowest because the available steam concentration is lower.

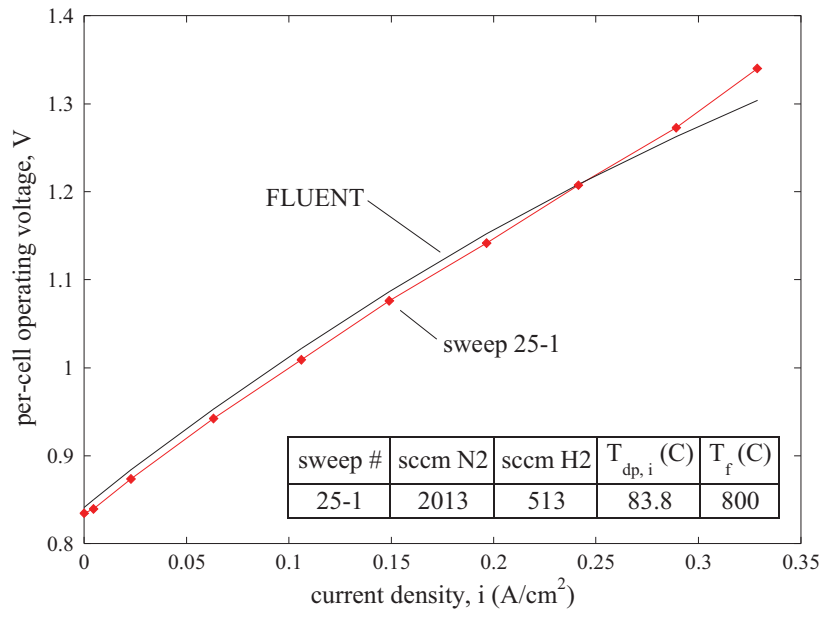

(a)

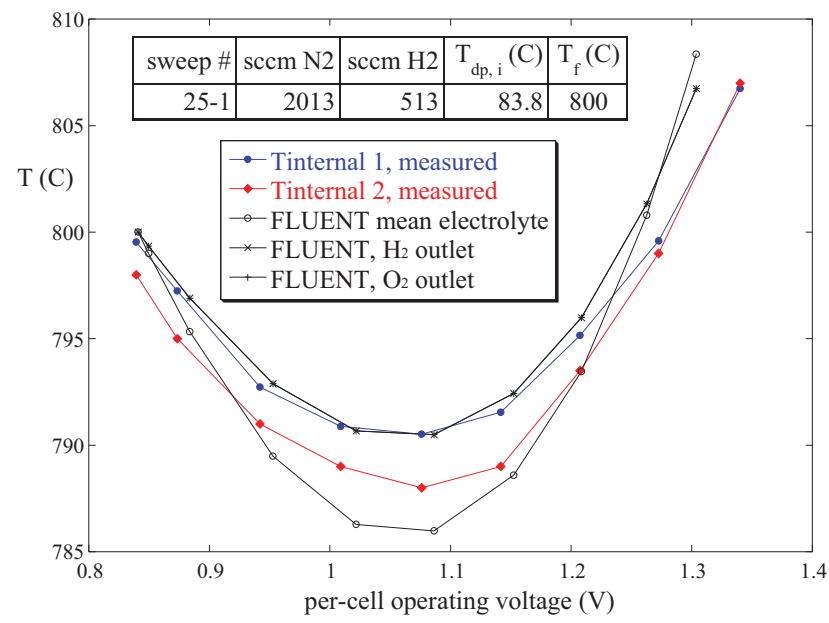

(b)

Figure 19. Comparison of internal stack temperature predictions with experimentally measured values. 


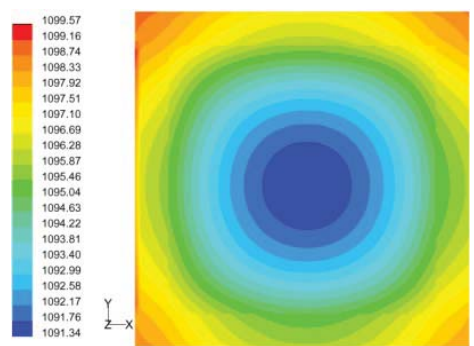

(a)

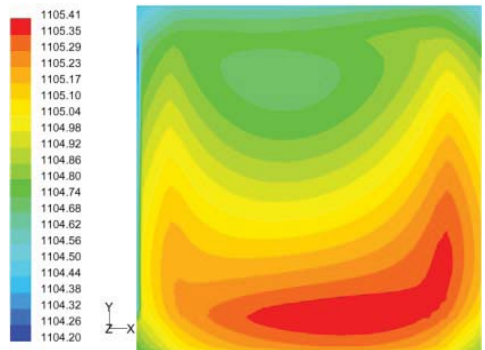

(b)

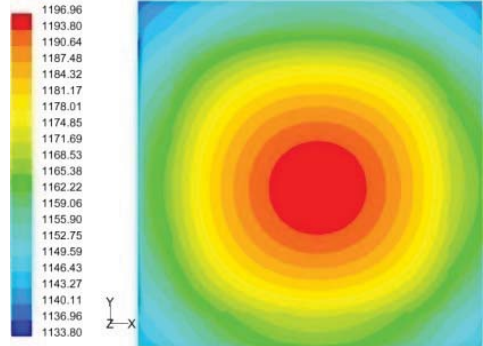

(c)

FIGURE 20. Temperature (K) contours on the electrolyte and insulator for currents of 10, 15, and 30 amps.
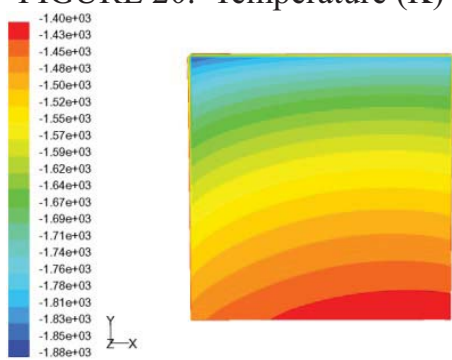

(a)
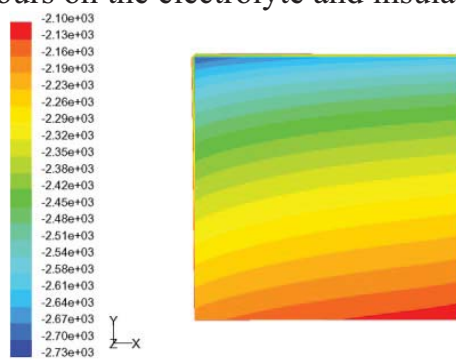

(b)
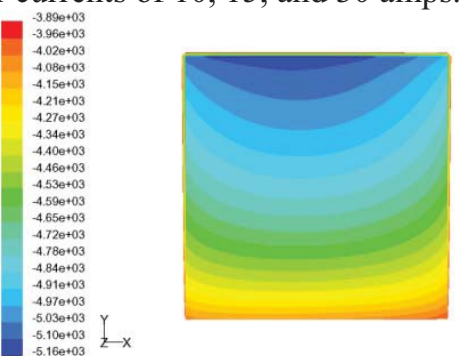

(c)

FIGURE 21. Current density $\left(\mathrm{A} / \mathrm{m}^{2}\right)$ contours on the electrolyte for currents of 10,15 , and $30 \mathrm{amps}$.

Additional detailed CFD models have been developed for the analysis of integrated planar solid oxide cells operating in the electrolysis mode $[54,55]$. These cells are deposited on a porous ceramic tube, with steam and hydrogen flowing in 15

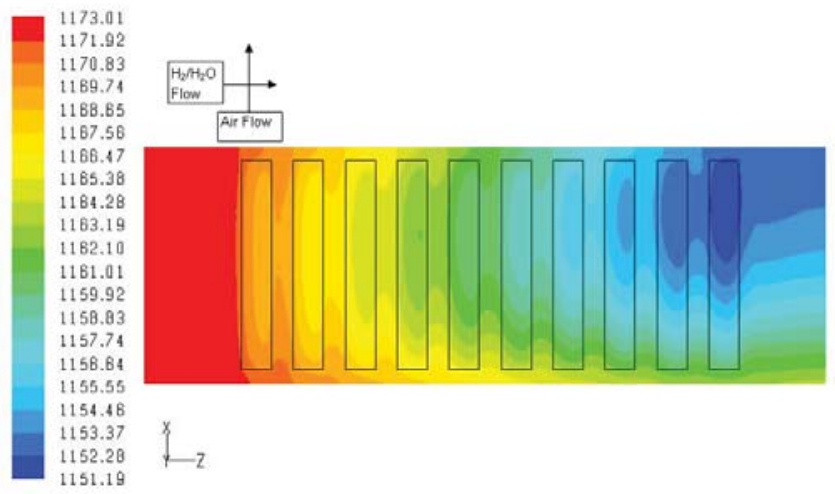

(a)

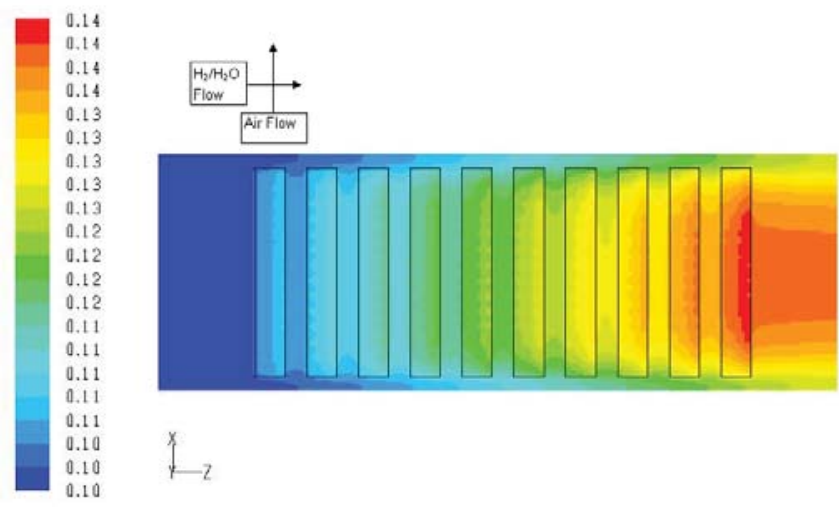

(b)

Figure 22. Surface temperature contours (a) and internal hydrogen mole fractions (b), integrated planar cells on ceramic tube. individual flow channels within the tube. Representative results are given in Fig. 22. Fig. 22(a) shows temperature contours on the surface of the ceramic tube for an operating voltage below thermal neutral. Fig. 22(b) shows the internal hydrogen mole fraction, increasing from left to right due to electrolysis. Transverse variations in the hydrogen mole fraction are associated with internal flows in the 15 individual flow tubes.

\section{SYSTEM ANALYSIS OF LARGE-SCALE HYDROGEN PRODUCTION PLANTS}

\section{System Models}

When considering the development of any new technology for possible large-scale application, it is important to study the technology from a variety of perspectives including fundamental experimental and computational studies as well as large-scale system simulation. Accordingly, a number of detailed process models have been developed at INL for largescale system analysis of high-temperature electrolysis plants including both steam electrolysis and co-electrolysis of steam and carbon dioxide $[15,21,56]$. These analyses have been performed using UniSim process analysis software [31] which inherently ensures mass and energy balances across all components and includes thermodynamic data for all chemical species.

For these simulations, the per-cell active area for electrolysis was assumed to be $225 \mathrm{~cm}^{2}$. This cell size is well within the limits of current technology for planar cells. Areaspecific resistance $(A S R)$ was used to characterize the performance of the electrolysis cells. This parameter incorporates the loss mechanisms in the cells. The ASR value used in the electrolyzer module is temperature-dependent using an empirically developed Arrhenius equation [35]. In order to show the trends that can be expected with higher or lower ASR, 
two values of $A S R_{1100 K}$ have been included in this study. The temperature dependence of the $A S R$ is important for nonisothermal cases and for evaluating the effect of electrolyzer inlet temperature on overall process efficiency.

The total number of cells used in the process simulations was determined by specifying a maximum current density for each $A S R$ value that was large enough to ensure that the operating voltage would just exceed the thermal neutral voltage. For the higher nominal $A S R$ value of $1.25 \mathrm{Ohm} \cdot \mathrm{cm}^{2}$, the maximum current density was set at $0.25 \mathrm{~A} / \mathrm{cm}^{2}$ and an adiabatic thermal boundary condition was assumed. The total number of cells for this base case was adjusted until the total remaining power was zero. In other words, the full power cycle output at this operating point is dedicated to electrolysis. This procedure resulted in $1.615 \times 10^{6}$ cells required. At lower current densities, the power cycle output exceeds the value required for electrolysis and this excess power would be supplied to the grid. For the case of $A S R=0.25 \mathrm{Ohm} \cdot \mathrm{cm}^{2}$, the maximum current density was set at $1.0 \mathrm{~A} / \mathrm{cm}^{2}$. A much higher maximum current density was required for the lower $A S R$ case, again in order to assure that the thermal neutral voltage was just exceeded.

Two thermal boundary condition limits were considered for the electrolyzer: isothermal and adiabatic. Actual electrolyzer operation will generally lie between these limits. For the isothermal cases, heat from the reactor was directly supplied to the electrolyzer to maintain isothermal conditions for operation below the thermal neutral voltage. Heat rejection from the electrolzer is required to maintain isothermal operation at operating voltages above thermal neutral.

To allow for comparisons between the performance of the HTE processes and alternate hydrogen production techniques, we have adopted a general efficiency definition (consistent with Eq. (4)) that can be applied to any thermal water-splitting process, including HTE, low-temperature electrolysis (LTE), thermochemical water splitting. Since the primary energy input to the thermochemical processes is in the form of heat, the appropriate general efficiency definition to be applied to all of the techniques is the overall thermal-to-hydrogen efficiency, $\eta_{H}$. This efficiency is defined as the heating value of the product hydrogen divided by the total thermal input required to produce it. In this report, the lower heating value, LHV, of the products has been used:

$$
\eta_{H}=\frac{\sum_{i} \dot{N}_{i} L H V}{\sum_{i} Q_{i}}
$$

The denominator in this efficiency definition quantifies all of the net thermal energy that is consumed in the process. For a thermochemical process, this summation includes the direct nuclear process heat as well as the thermal equivalent of any electrically driven components such as pumps, compressors, etc. The thermal equivalent of any electrical power consumed in the process is the power divided by the thermal efficiency of the power cycle. The power-cycle thermal efficiency for the helium-cooled direct Brayton cycle concept described in this paper was $52.6 \%$. For an electrolysis process, the summation in the denominator of Eq. (29) includes the thermal equivalent of the primary electrical energy input to the electrolyzer and the secondary contributions from smaller components such as pumps and compressors. In additional, any direct thermal inputs are also included. Direct thermal inputs include any net (not recuperated) heat required to heat the process streams up to the electrolyzer operating temperature and any direct heating of the electrolyzer itself required for isothermal operation. The numerator of Eq. (29) is specified in terms of a summation of heating values that could include hydrogen plus additional HTE products such as carbon monoxide.

\section{Representative System Analysis Results}

A summary of results obtained from the hydrogen production system analyses is presented in Figs. $23-25$. The results presented in Figs. 23 and 24 were obtained for a fixed steam utilization of $89 \%$ (i.e., $89 \%$ of the inlet steam was converted to hydrogen). In order to maintain fixed steam utilization, the flow rates of the process streams were adjusted, yielding lower flow rates for lower current densities and higher flow rates for higher current densities. Results of eight cases are presented in Fig. 23: low and high $A S R$, adiabatic and isothermal electrolyzer operation, air-sweep and no-sweep. The figure provides overall hydrogen production efficiencies (Eq. 29) as a function of per-cell operating voltage. Recall that electrolyzer efficiency is inversely proportional to operating voltage (Eq. (22)). Higher operating voltages yield higher current densities and higher hydrogen production rates, but lower overall efficiencies, so the selection of electrolyzer operating condition is a tradeoff between production rate and efficiency. For a specified target production rate, higher production efficiency requires higher capital cost, since more cells would be required to achieve the target production rate at lower current density. In general, a good tradeoff between production rate and efficiency occurs for cell operating voltages near or slightly below the thermal neutral value, around $1.29 \mathrm{~V}$. This operating voltage is also desirable from the standpoint that the electrolysis stack operates nearly isothermally at this voltage. Predicted overall thermal-to-hydrogen efficiency values shown in Fig. 23 are generally within 8 percentage points of the power-cycle efficiency of $52.6 \%$ (direct helium Brayton cycle with $850^{\circ} \mathrm{C}$ reactor outlet), decreasing with operating voltage. It is interesting to note that the overall process efficiencies for these fixed-utilization cases collapse onto individual lines, one for the air-sweep cases and another for the no-sweep cases, when plotted as a function of cell operating voltage, regardless of the electrolyzer mode of operation (adiabatic or isothermal) and ASR value. Note that the highest operating voltages shown are just above the thermal neutral voltage of $1.29 \mathrm{~V}$. Note also that the highest overall efficiency plotted in Fig. 23 (for no-sweep, $A S R=0.25$, isothermal, $\mathrm{V}=1.06 \mathrm{~A} / \mathrm{cm}^{2}$ ) exceeds $51 \%$.

An additional line, based on a simple thermodynamic analysis [57] is also shown in Fig. 23. This analysis considers a control volume drawn around the electrolysis process, with the process consuming the electrical work from the power cycle, 


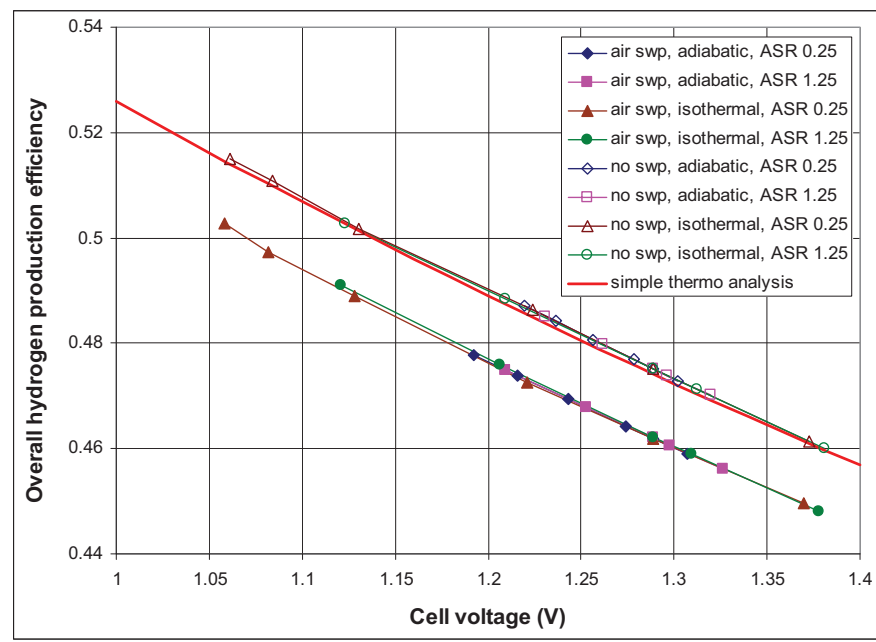

Figure 23. Overall HTE hydrogen production efficiencies for the VHTR/recuperated direct Brayton cycle, as a function of cell operating voltage.

and heat from a high-temperature source. If the inlet and outlet streams are assumed to be liquid water, and gaseous hydrogen and oxygen, respectively, at $T=T^{\circ}, P=P^{o}$, direct application of the first law, Faraday's law, and the definition of the overall thermal-to-hydrogen efficiency yields:

$$
\eta_{H}=\frac{L H V}{2 F V_{o p}\left(1 / \eta_{t h}-1\right)+H H V}
$$

The curve labeled "simple thermo analysis" in Fig. 23 represents Eq. (30). This equation provides a useful reference against which results of detailed system analyses can be measured. The simple thermodynamic analysis agrees quite closely with the detailed system analysis results for the nosweep cases, which correspond directly with the conditions of simple analysis since it does not include consideration of a sweep gas. Overall hydrogen efficiency results of the air-sweep cases are about $1 \%$ lower than the no-sweep cases.

Hydrogen production efficiencies can also be plotted as a function of hydrogen production rate, as shown in Fig. 24. As expected, efficiencies decrease with production rate since higher production rates require higher current densities and higher per-cell operating voltages, for a fixed number of cells. For this plot, the full $600 \mathrm{MW}_{\text {th }}$ output of the reactor is assumed to be dedicated to hydrogen production. Under this assumption about four times as many electrolysis cells are required for the high-ASR cases than for the low-ASR cases, with a correspondingly higher associated capital cost. Fig. 24 also shows that hydrogen production rates in excess of $2.3 \mathrm{~kg} / \mathrm{s}$ $\left(92,000 \mathrm{SCMH}, 78 \times 10^{6} \mathrm{SCF} /\right.$ day $)$ could be achieved with a dedicated $600 \mathrm{MW}_{\text {th }}$ hydrogen-production plant. This rate is the same order of magnitude as a large hydrogen production plant based on steam-methane reforming [58]. Fig. 24 indicates similar overall efficiencies for the low- $A S R$ and high- $A S R$ cases at a specified electrolyzer thermal operating condition (adiabatic or isothermal) and hydrogen production rate.
The effect of steam utilization on overall system performance was examined by fixing the electrolyzer inlet process gas flow rates at the values corresponding to the highest current density achievable with each $A S R$ value, then varying the current density over the full range of values considered for the fixed-utilization cases. Low current densities for this case yield low values of steam utilization since the inlet steam flow rate is fixed at a value that yields $89 \%$ utilization at the highest current density. Results of this exercise are presented in Fig. 25. The overall efficiency results for the variable-utilization cases nearly collapse onto a single curve when plotted versus utilization. The plot indicates a strong dependence on utilization, with overall hydrogen production efficiencies less than $25 \%$ at the lowest utilization values shown $(\sim 5.5 \%)$, increasing to a maximum value of $\sim 47 \%$ at the highest utilization value considered (89\%). So, from the overall system perspective, low steam utilization is undesirable. This is an interesting result because, from the perspective of the electrolyzer alone, low utilization yields high electrolyzer (not overall) efficiency values. Excess steam in the electrolyzer keeps the average Nernst potential low for each cell, which assures a low operating voltage for a specified current density (or hydrogen production rate). However, from the overall system perspective, low steam utilization means that the system is processing lots of excess material, resulting in relatively high irreversibilities associated with incomplete heat recuperation, pumping and compression of excess process streams, etc. Above $\sim 50 \%$ utilization, however, the efficiency curves are relatively flat, even decreasing slightly for the isothermal cases. Regarding very high utilization values, achievement of steam utilization values much above $90 \%$ is not practical from an operational standpoint because localized steam starvation can occur on the cells, with associated severe performance penalties and possible accelerated cell lifetime degradation. Results shown in Fig. 25 are consistent with results presented in references $[59,60]$, both in terms of the magnitude of the overall hydrogen production efficiency values and in terms of the trend with respect to steam utilization.

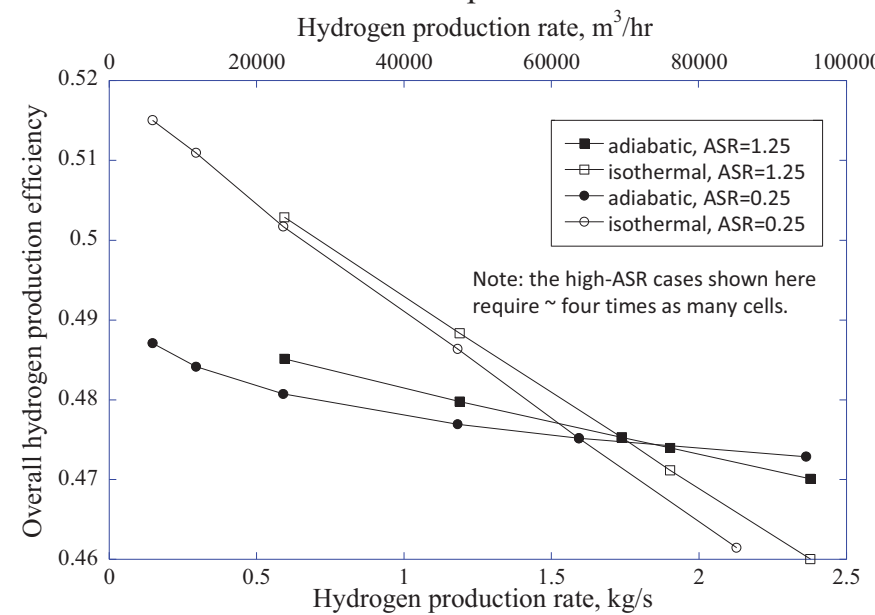

Figure 24. Overall hydrogen production efficiency as a function of hydrogen production rate, with air sweep. 


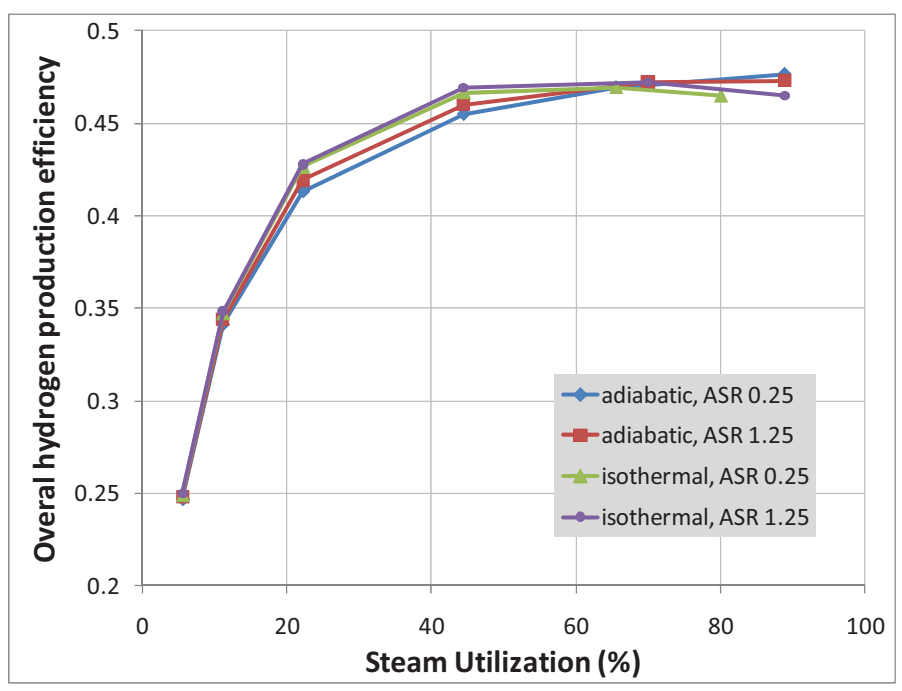

Figure 25. Effect of steam utilization on overall hydrogen production efficiency.

\section{DEPLOYMENT OPTIONS, ECONOMICS, AND POTENTIAL IMPACT}

A continuum of possible deployment magnitudes and implementation strategies can be considered for nuclear hydrogen production. One possible early deployment strategy is to tie the hydrogen production process to the grid and make use of inexpensive off-peak electricity. This strategy would not require a large capital investment since only the electrolyzers would be required. Hydrogen could be produced via HTE using grid electricity (HTE requires $\sim 32 \mathrm{~kW} \cdot \mathrm{hr} / \mathrm{kg}_{\mathrm{H} 2}$ ) and natural gas-based process heat for less than $\$ 2.0 / \mathrm{kg}$, assuming an electricity cost of $\$ 5.00 / \mathrm{MW} \cdot \mathrm{hr}$, a heat cost of $\$ 5.00 / \mathrm{MBTU}$, an SOEC capital cost of $\$ 200 / \mathrm{kW}$ (based on demonstrated SECA [39] cost target of $\$ 400 / \mathrm{kW}$ for SOFCs), and a stack life of $40,000 \mathrm{hr}$. This production cost is competitive today. Of course, this method of hydrogen production is not carbon-free, since grid electricity is used and the process heat is based on natural gas. Nevertheless, initial HTE deployments will undoubtedly be based on this type of concept, rather than a fullscale dedicated nuclear hydrogen plant.

Another example of a potential early deployment concept for HTE has been proposed by Forsberg [27]. He has performed a study of a concept in which hydrogen and oxygen are produced from grid electricity during off-peak times when electricity prices are low, stored underground, and subsequently fed into a combustor and advanced high-temperature steam turbine for efficient electrical generation during peak price time periods. The economics of this concept work out favorably for electrical grids that exhibit large differences in electricity prices between low-demand and high-demand time periods.

A preliminary economic analysis has also been performed to estimate the hydrogen production cost for a large-scale dedicated HTE plant coupled to an advanced high-temperature gas-cooled reactor [61]. The reference HTE plant considered for this particular analysis was driven by a $600 \mathrm{MW}_{\mathrm{t}}$ high-temperature helium-cooled reactor coupled to a direct Brayton power cycle with a reactor outlet temperature of $900^{\circ} \mathrm{C}$. Plant operating conditions used in the reference plant optimization were based on parametric studies performed using UniSim [31] process analysis software. The economic analysis was performed using the standardized H2A Analysis Methodology developed by the Department of Energy (DOE) Hydrogen Program [62], using realistic financial and cost estimating assumptions. Based on this methodology, and the various assumptions discussed in detail in reference [61], the estimated price of the hydrogen leaving the plant gate at $5 \mathrm{MPa}$ pressure would be $\$ 3.23 / \mathrm{kg}$. This estimated price was shown to be most sensitive to the assumed after-tax internal rate of return (nominal assumed value was $10 \%$ ) and the cost of unplanned replacement costs. This estimated lifecycle HTE hydrogen production cost represents the cost of hydrogen leaving the plant gate, and does not include any additional storage, delivery, fuel taxes or other costs that the consumer might pay at the pump. Compared to the current hydrogen commodity price of about $\$ 2.50 / \mathrm{kg}$ (based on steam-methane reforming), this estimated cost is not unreasonable considering the volatility of the cost of the natural gas and the fact that the HTE technology does not emit greenhouse gases. Estimates of hydrogen production cost based on LTE depend strongly on electricity prices, but for large systems (1000 kg/day), with an assumed industrial electricity cost of $\$ 0.0483 / \mathrm{kWh}$, a hydrogen selling price of $\$ 4.15$ (FY2000 dollars) has been reported [63], based on the DOE H2A methodology. Note that any proposed new technology for large-scale hydrogen production must at a minimum be able to compete with this price.

In the short term, demand for hydrogen is primarily tied to petroleum upgrading and ammonia production. Therefore, short-term strategies should be focused on meeting these demands in a cost-competitive fashion. In terms of penetrating the transportation market, supplemental non-fossil hydrogen can be used for refining and upgrading petroleum. Demand for hydrogen for this purpose is growing dramatically as increasingly lower quality petroleum resources such as oil sands and heavy crudes are exploited. For example, several large steam methane reforming (SMR) hydrogen production plants are located near Edmonton, Alberta to enable the conversion of oil sands into a synthetic crude oil that can then be further processed by traditional refineries. These large SMR plants have a typical hydrogen production capacity on the order of 100 million standard cubic feet per day (SCFD), while consuming about 33 million SCFD of natural gas and emitting 49 million SCFD of $\mathrm{CO}_{2}$ into the atmosphere [64]. The total oil-sands natural gas consumption rate is currently around 1.4 billion SCFD, with the projected demand by 2015 at 2.1 billion SCFD [65]. With traditional SMR, natural gas is consumed both as a feedstock to the reformer and to provide the hightemperature process heat required to overcome the endothermic heat requirement of the reformation reaction at $800-850^{\circ} \mathrm{C}$. The upgrading requirement for bitumen using natural gas-based hydrogen results in life-cycle greenhouse gas (GHG) emissions that are $16 \%$ higher than the LCA emissions associated with light crude production and utilization. The increased LCA 
emissions for Venezuelan heavy crude are similar [66]. Implementation of an alternate GHG-free hydrogen production strategy, such as nuclear-powered HTE would relieve some of the demand for natural gas while reducing LCA GHG emissions.

The scale of these SMR plants provides a basis of comparison to proposed nuclear HTE plants. A $600 \mathrm{MW}_{\text {th }}$ high-temperature reactor coupled to a dedicated HTE plant would have a hydrogen production capacity of about 85 million SCFD [56], very similar to a large SMR plant. The economics of the nuclear-HTE option will improve as the demand for natural gas increases and reserves are depleted. The expected implementation of carbon taxes will also have an impact.

Beyond providing hydrogen for upgrading petroleum resources, HTE can also be used to support the production of synthetic fuels from non-conventional carbon sources such as biomass [26] or coal [66], or directly from carbon dioxide via co-electrolysis [21].

Hydrogen can also be employed as a direct transportation fuel. Many books and articles have been written on the topic of "The Hydrogen Economy," some advocating strongly for the concept [68] and others concluding that the idea is ill-founded [69]. From an environmental perspective, the concept is certainly appealing, provided that the required hydrogen production is based on water splitting with clean carbon-free energy sources such as renewables or nuclear. In this case, hydrogen-powered transportation has the potential to relieve the growing demand for petroleum and natural gas, while simultaneously addressing concerns about emissions of greenhouse gases and other atmospheric pollutants. The concept also provides a mechanism that allows nuclear and renewable energy sources to contribute to the transportation sector, which is currently $95 \%$ powered by fossil fuels [70]. Of course, electric vehicles can also enable some penetration of grid electricity and nuclear into the transportation sector.

The supplemental power required to produce enough hydrogen to accomplish a specified impact can easily be estimated. For example, what additional electric power would be required to replace all light-duty vehicles in the US with hydrogen fuel-cell vehicles (FCVs)? The total number of lightduty vehicle miles traveled in the US in 2008 was estimated to be 2676 billion miles [71]. Several automobile manufacturers have active FCV development and demonstration programs. These demonstrations have provided early data on expected FCV hydrogen fuel economy. In August 2009, Toyota completed a DOE field evaluation of its Highlander (mid-size SUV) fuel cell hybrid vehicle, achieving an average fuel economy of $68.3 \mathrm{miles} / \mathrm{kg}$ for a 331-mile trip in California. In November, 2009, Toyota, Honda, and Nissan participated in a 706-mile demonstration run of their prototype FCVs in Japan, achieving an average $73.6 \mathrm{miles} / \mathrm{kg}$. Based on these tests, an assumed average FCV fuel efficiency for future production vehicles of $60 \mathrm{miles} / \mathrm{kg}$ is very reasonable. The electrical energy requirement for commercially available atmospheric low-temperature electrolysis is $45.6 \mathrm{~kW} \cdot \mathrm{hr} / \mathrm{kg}$ [72]. An additional $3.3 \mathrm{~kW} \cdot \mathrm{hr} / \mathrm{kg}$ is required for compression from atmospheric pressure to $30 \mathrm{MPa}$ (typical compressed hydrogen on-board-vehicle storage pressure), for a total of 48.9 $\mathrm{kW} \cdot \mathrm{hr} / \mathrm{kg}$. Based on these numbers, the total electrical power required to supply enough hydrogen to provide all the lightduty vehicle miles driven in the US in 2008 is $254 \mathrm{GW}$. This result is similar to a result given by Walters [73] based on a similar analysis. For comparison, the total electrical energy consumed in the US in 2007 was $4.16 \times 10^{9} \mathrm{MW} \cdot \mathrm{hr}$ [74], which corresponds to an average consumption rate of $474 \mathrm{GW}$. The total installed "nameplate" electric generating capacity in the US in 2007 was $1088 \mathrm{GW}$. Based on this difference between installed capacity and average utilization, there is significant potential to power hydrogen production from the grid right now, without adding any additional generating capacity.

Construction plans for the first new nuclear power units to be built in the US in 30 years were recently announced. These units will be rated at $1100 \mathrm{MW}$ each. Therefore, if the generating capacity needed for hydrogen production to replace all light-duty vehicle miles were to be met by the installation of similar new nuclear plants, 230 new 1100-MW units would be required. Compared to the 104 nuclear plants now in service in the US, this is not an outrageous number. If this electrical power were to be generated using wind power, 677,000 large 1.5 MW windmills (assumed capacity factor of 0.25 ) would be needed. The windmills would be distributed over a land area of about 74,000 square miles (70 acre footprint per windmill), more than twice the land area of the state of Indiana.

The preceding analysis was based on conventional electrolysis. The electrical energy requirement for HTE is $30-$ $35 \mathrm{~kW} \cdot \mathrm{hr} / \mathrm{kg}$, depending on cell performance and operating conditions. Using $32 \mathrm{~kW} \cdot \mathrm{hr} / \mathrm{kg}$, and the same $3.3 \mathrm{~kW} \cdot \mathrm{hr} / \mathrm{kg}$ for compression work, the total electrical requirement for HTE is $35.3 \mathrm{~kW} \cdot \mathrm{hr} / \mathrm{kg}$, which is $34 \%$ lower than for conventional electrolysis. The corresponding total electrical generating capacity required to supply enough hydrogen to provide all the light-duty vehicle miles driven in the US in 2008 would be 183 GW. HTE also requires high-temperature process heat. With a dedicated nuclear-HTE plant, such as the one shown conceptually in Fig. 1, this process heat would be supplied directly to the HTE unit via an intermediate heat exchanger. Current concepts for this application envision a $600 \mathrm{MW}$ hightemperature helium-cooled reactor with an outlet temperature of approximately $800^{\circ} \mathrm{C}$. Assuming a power cycle thermal efficiency of $50 \%$ (reasonable for high-temperature reactors), just over 600 of these smaller high-temperature nuclear reactors would be required to supply the needed $183 \mathrm{GW}$.

In addition to supporting petroleum upgrading, potential markets for hydrogen and HTE can be defined in the area of synthetic fuels production. For example, distributed production of synthetic liquid fuels based on biomass and supplemental hydrogen offers a method of producing carbon-neutral liquid fuels such as biodiesel and ethanol [26]. The high temperature process heat for HTE can be provided by the biomass gasifier while the oxygen required for the gasifier is produced as a byproduct of the HTE process. Supplemental hydrogen from electrolysis enables achievement of high carbon utilization such 
that about $95 \%$ of the carbon in the biomass feedstock is retained in the syngas product. Oxygen produced from the electrolysis process is used to control the oxidation rate in the oxygen-fed biomass gasifier. Syngas production efficiencies range from $70 \%$ to $73 \%$, depending on the gasifier temperature.

\section{SUMMARY AND CONCLUSIONS}

With growing demand for hydrogen for petroleum refining, ammonia and synthetic fuels production and other applications, alternate sources of hydrogen are being developed. High temperature thermal water splitting processes in general and high temperature steam electrolysis in particular offer relatively efficient carbon-free options for large-scale hydrogen production. HTE makes use of solid oxide electrolysis cells to electrochemically split steam into hydrogen and oxygen at about $850^{\circ} \mathrm{C}$. The overall thermal-to-hydrogen efficiency of HTE can approach $50 \%$, based on the lower heating value of the produced hydrogen. The feasibility of this technology has been demonstrated up to the $15 \mathrm{~kW}$ scale. Heat and mass transfer phenomena in SOECs can be modeled with a variety of CFD tools to predict the details of cell and stack performance under a variety of operating conditions. Large-scale system analyses have provided a favorable assessment of the overall performance of large-scale hydrogen production schemes based on HTE. A variety of short and long-term deployment options for HTE have been discussed, many of which provide a path for carbon-free energy sources such as nuclear to contribute directly to the transportation sector.

\section{ACKNOWLEDGMENTS}

This work was supported by the U.S. Department of Energy, Office of Nuclear Energy, Nuclear Hydrogen Initiative and Next Generation Nuclear Plant Programs under DOE Operations Office Contract DE-AC07-05ID14517.

\section{REFERENCES}

1. Forsberg, C. W., "The Hydrogen Economy is Coming. The Question is Where?" Chemical Eng. Progress, Dec. 2005, pp. 20-22.

2. Lewis, D., "Hydrogen and its relationship with nuclear energy," Progress in Nuclear Energy, Vol. 50, pp. 394-401, 2008.

3. Kruger, P., "Nuclear Production of Hydrogen as an Appropriate Technology," Nuclear Technology, Vol. 166, pp. 11-17, 2009.

4. Forsberg, C. W., "Future hydrogen markets for large-scale hydrogen production systems," Int. J. Hydrogen Energy, Vol. 32, pp. 431-439, 2007.

5. Duffey, R. B., "Nuclear production of hydrogen: When worlds collide," International Journal of Energy Research," Vol. 33, pp. 126-134, 2009.

6. Granovskii, M., Dincer, I., and Rosen, M. A., "Greenhouse gas emissions reduction by use of wind and solar energies for hydrogen and electricity production: economic factors," Int. J. Hydrogen Energy, V. 32, 2007, pp. 927-931.
7. Rand, D. A. J., and Dell, R. M., Hydrogen Energy: Challenges and Prospects, Royal Society of Chemistry, 2008.

8. Floch, P-H., Gabriel, S., Mansilla, C., and Werkoff, F., “On the production of hydrogen via alkaline electrolysis during off-peak periods," Int. J. Hydrogen Energy, Vol. 32, 2007, pp. 4641-4647.

9. Schultz, K. R., Brown, L. C., Besenbruch, G. E. and Hamilton, C. J., "Large-Scale Production of Hydrogen by Nuclear Energy for the Hydrogen Economy," Report GAA24265, Feb. 2003, 22p.

10. O'Brien, J. E., Stoots, C. M., Herring, J. S., and Hartvigsen, J. J., "Performance of Planar HighTemperature Electrolysis Stacks for Hydrogen Production from Nuclear Energy," Nuclear Technology, Vol. 158, pp. 118 - 131, May, 2007.

11. Steinfeld, A. "Solar thermochemical production of hydrogen," Solar Energy, V 78, No 5, pp. 603-615, May 2005.

12. Southworth, F., Macdonald, P. E., Harrell, D. J., Park, C. V., Shaber, E. L., Holbrook, M. R., and Petti, D. A., "The Next Generation Nuclear Plant (NGNP) Project," Proceedings, Global 2003, pp. 276-287, 2003.

13. Elder, R., and Allen, R., "Nuclear heat for hydrogen production: Coupling a very high/high temperature reactor to a hydrogen production plant," Progress in Nuclear Energy, Vol. 51, pp. 500-525, 2009.

14. Yildiz, B., and Kazimi, M. S., "Efficiency of Hydrogen Production Systems Using Alternative Nuclear Energy Technologies," Int. J. of Hydrogen Energy, Vol. 31, pp. 77-92, 2006.

15. O’Brien, J. E., McKellar, M. G., and Herring, J. S., "Performance Predictions for Commercial-Scale HighTemperature Electrolysis Plants Coupled to Three Advanced Reactor Types," 2008 International Congress on Advances in Nuclear Power Plants, June 8-12, 2008, Anaheim, CA.

16. Utgikar, V., and Thiesen, T., "Life cycle assessment of high temperature electrolysis for hydrogen production via nuclear energy," International Journal of Hydrogen Energy, Vol. 31, pp. 939-944, 2006.

17. Friedrich, R., Rabl, A., and Spadaro, J. V., "Quantifying the Costs of Air Pollution: the ExternE Project of the EC," Pollution Atmospherique, pp. 77 - 104, Dec. 2001.

18. Jacobsen, M. Z., "Review of Solutions to Global Warming, Air Pollution, and Energy Security," Energy and Environmental Science, Vol. 2, pp. 148 - 173, 2009.

19. Schultz, K., Sink, Pickard, P., Herring, J. S., O’Brien, J. E., Buckingham, R., Summers, W., and Michele Lewis, M., "Status of the US Nuclear Hydrogen Initiative," Proceedings of ICAPP 2007, Paper 7530, Nice, France, May 13-18, 2007; The Nuclear Renaissance at Work, V. 5, Societe Francaise d'Energie Nucleaire - ICAPP 2007, pp. 2932-2940.

20. Varrin, R. D., Reifsneider, K., Scott, D. S., Irving, P., and Rolfson, G., "NGNP Hydrogen Technology Down- 
Selection; Results of the Independent Review Team Evaluation," Dominion Engineering report\# R-6917-00-01, August, 2009.

21. O’Brien, J. E., McKellar, M. G., Stoots, C. M., Herring, J. S., and Hawkes, G. L., "Parametric Study of Large-Scale Production of Syngas via High Temperature Electrolysis," International Journal of Hydrogen Energy, Vol. 34, pp. 4216-4226, May, 2009.

22. Stoots, C. M., O’Brien, J. E., "Results of Recent HighTemperature Co-electrolysis Studies at the Idaho National Laboratory," in press, International Journal of Hydrogen Energy, Vol. 34, Issue 9, pp. 4208-4215, May 2009.

23. Jensen, S. H., Larsen, P. H., Mogensen, M., "Hydrogen and synthetic fuel production from renewable energy sources," Int. J. Hydrogen Energy, Vol. 32, pp. 3253-3257, 2007.

24. Mogensen, M., Jensen, S. H., Hauch, A., Chorkendorff, lb., and Jacobsen, T., "Reversible Solid Oxide Cells, " Ceramic Engineering and Science Proceedings, V 28, n 4, Advances in Solid Oxide Fuel Cells III - A Collection of Papers Presented at the 31st International Conference on Advanced Ceramics and Composites, 2008, p 91-101.

25. Arashi, H., Naito, H., and Miura, I., "Hydrogen Production from High-Temperature Steam Electrolysis using Solar Energy," Int. J. Hydrogen Energy, Vol. 16, No. 9, pp. 603$608,1991$.

26. Hawkes, G. L. and McKellar, M. G., "Liquid Fuel Production from Biomass via High Temperature Steam Electrolysis," 2009 AIChE Annual Meeting, November 8 13, 2009, Nashville, TN.

27. Forsberg, C. W., "Economics of Meeting Peak Electricity Demand using Hydrogen and Oxygen from Base-Load Nuclear or Off-Peak Electricity," Nuclear Technology, Vol. 166, pp. 18-26, 2009.

28. Nomura, M., Kasahara, S., and Onuki, K., "Estimation of Thermal Efficiency to produce Hydrogen from Water through IS Process," Proc., 2nd Topical Conference on Fuel Cell Technology, AIChE Spring National Meeting, New Orleans, 2003.

29. Abraham, B. M., and Schreiner, F., "General Principles Underlying Chemical Cycles which Thermally Decompose Water into the Elements," Ind. Eng. Chem. Fundam., Vol. 13, No. 4, 1974.

30. Fletcher, E. A., and Moen, R. L., "Hydrogen and Oxygen from Water," Science, Vol. 197, pp. 1050-1056, 1977.

31. UniSim Design, R360 Build 12073, Copyright (C20052006 Honeywell International Inc.

32. Brown, L. C., Lentsch, R. D., Besenbruch, G. E., Schultz, K. R., "Alternative Flowsheets for the Sulfur-Iodine Thermochemical Hydrogen Cycle," AIChE Journal, April 2003.

33. Larminie, J. and Dicks, A., Fuel Cell Systems Explained, John Wiley \& Sons, New York, 2003.

34. O'Brien, J. E., Stoots, C. M., and Hawkes, G. L., "Comparison of a One-Dimensional Model of a HighTemperature Solid-Oxide Electrolysis Stack with CFD and Experimental Results," Proceedings, 2005 ASME
International Mechanical Engineering Congress and Exposition, Orlando, Nov. 5 - 11, 2005.

35. Stoots, C. M., O’Brien, J. E., McKellar, M. G., Hawkes, G. L., and Herring, J. S., "Engineering Process Model for High-Temperature Steam Electrolysis System Performance Evaluation," AIChE 2005 Annual Meeting, Cincinnati, Oct. 30 - Nov. 4, 2005.

36. Steinberger-Wilkens, R. Tietz, F., Smith, M. J., Mougin, J., Rietveld, B., Bucheli, O., Van Herle, J., Mohsine, Z., and Holtappels, P., "Real-SOFC - A Joint European Effort in Understanding SOFC Degradation," ECS Transactions, v 7, $\mathrm{n} 1$ PART 1, ECS Transactions - 10th International Symposium on Solid Oxide Fuel Cells, SOFC-X, pp. 6776, 2007.

37. Ishihara, T., Hiroyuki, E, Zhong, H. and Matsumoto, H., "Intermediate Temperature Solid Oxide Fuel Cells using LaGaO3 based Perovskite Oxide for Electrolyte," Electrochemistry, Vol. 77, No. 2, pp. 155-157, February, 2009.

38. Singhal, S. C., and Kendall, K., Solid Oxide Fuel Cells, Elsevier Advanced Technology, Oxford, UK, 2003.

39. Surdoval, W. A., "U.S. Department of Energy's SECA Program: 2008 Progress and Plans," ECS Transactions, Vol. 17, No. 1, pp. 3-7, 2009.

40. Borglum, B., "Development of Solid Oxide Fuel Cells at Versa Power Systems," 2008 Fuel Cell Seminar, Phoenix, October 28, 2008.

41. Nichols, D. K., Agnew, G. D., Strickland, D., "Outlook and Application Status of the Rolls-Royce Fuel Cell Systems SOFC," IEEE Power and Energy Society 2008 General Meeting, Pittsburgh, July 20 -24, 2008.

42. O’Brien, J. E., Stoots, C. M., Herring, J. S., Lessing, P. A., Hartvigsen, J. J., and Elangovan, S., "Performance Measurements of Solid-Oxide Electrolysis Cells for Hydrogen Production," Journal of Fuel Cell Science and Technology, Vol. 2, pp. 156-163, August 2005.

43. O’Brien, J. E., Stoots, C. M., Herring, J. S., and Hartvigsen, J. J., "Hydrogen Production Performance of a 10-Cell Planar Solid-Oxide Electrolysis Stack," Journal of Fuel Cell Science and Technology, Vol. 3, pp. 213-219, May, 2006.

44. Housley, G., Condie, K., O’Brien, J.E., Stoots, C.M., "Design of an Integrated Laboratory Scale Experiment for Hydrogen Production via High Temperature Electrolysis," paper no. 172431, ANS Embedded Topical: International Topical Meeting on the Safety and Technology of Nuclear Hydrogen Production, Control, and Management, June 24 28, 2007, Boston, Massachusetts, USA.

45. Stoots, C. M., O'Brien, J. E., "Initial Operation of the High-Temperature Electrolysis Integrated Laboratory Scale Experiment at INL," 2008 International Congress on Advances in Nuclear Power Plants, June 8-12, 2008, Anaheim, CA.

46. Stoots, C. M., O’Brien, J. E., Condie, K., Moore-McAteer, L., Housley, G. K., Hartvigsen, J. J., and Herring, J. S., 
"The High-Temperature Electrolysis Integrated Laboratory Experiment," Nuclear Technology, April, 2009.

47. Housley, G. K., O’Brien, J. E., and Hawkes, G. L., "Design of a Compact Heat Exchanger for Heat Recuperation from a High Temperature Electrolysis System," 2008 ASME International Congress and Exposition, paper\# IMECE2008-68917, Boston, Nov., 2008.

48. Stoots, C. M., Condie, K. G., O’Brien, J. E., Herring, J. S., and Hartvigsen, J. J., "Test Results from the Idaho National Laboratory $15 \mathrm{~kW}$ High Temperature Electrolysis Test Facility," International Conference on Nuclear Energy, no. ICONE17-75417, Brussels, Belgium, July 12-16, 2009.

49. Stoots, C. M., O’Brien, J. E., Condie, K., Moore-McAteer, L., Housley, G. K., Hartvigsen, J. J., and Herring, J. S., "The High-Temperature Electrolysis Integrated Laboratory Experiment," Nuclear Technology, Vol. 166, No. 1, pp. 32 - 42, April, 2009.

50. VanderSteen, J. D. J., "Modeling Radiation Heat Transfer with Participating Media in Solid Oxide Fuel Cells," Journal of Fuel Cell Science and Technology, Vol. 3, No. 1, pp. $62-67$, February 2006.

51. Prinkey, M., Shahnam, M., and Rogers, W. A., "SOFC FLUENT Model Theory Guide and User Manual," Release Version 1.0, FLUENT, Inc., 2004.

52. FLUENT Theory Manual, version 6.1.22, Fluent Inc., Lebanon, New Hampshire, 2004.

53. Hawkes, G. L., O’Brien, J. E., Stoots, C. M., Herring, J. S., Shahnam, M., "CFD Model of a Planar Solid Oxide Electrolysis Cell for Hydrogen Production from Nuclear Energy," 11th Int. Topical Meeting on Nuclear Reactor Thermal-Hydraulics NURETH-11, Popes Palace Conference Center, Avignon, France, October 2-6, 2005.

54. Hawkes, G. L., O’Brien, J. E., Haberman, B., Marquis, A. J., Martinez Baca, C., Tripepi, D., Costamagna, P., "Numerical Prediction of Performance of Integrated Planar Solid Oxide Fuel Cell, With Comparison of Results from Several Codes," $6^{\text {th }}$ Int. Fuel Cell Science, Engineering \& Technology Conference, paper \#65179, June 16-18, 2008, Denver, CO.

55. Hawkes, G. L., O’Brien, “3D CFD Electrochemical and Heat Transfer Model of an Integrated-Planar Solid Oxide Electrolysis Cell," 2008 ASME International Congress and Exposition, paper\# IMECE2008-68866, Boston, Nov., 2008.

56. O’Brien, J. E., McKellar, M. G., Harvego, E. A., and Stoots, C. M., "High-Temperature Electrolysis for LargeScale Hydrogen and Syngas Production from Nuclear Energy - System Simulation and Economics," International Conference on Hydrogen Production, ICH2P09, Oshawa, Canada, May 3-6, 2009.

57. O’Brien, J. E., “Thermodynamic Considerations for Thermal Water Splitting Processes and High-Temperature Electrolysis," 2008 ASME International Congress and Exposition, paper\# IMECE2008-68880, Boston, Nov., 2008.
58. Ratan, S., Baade, W., and Wolfson, D. "The Large Hydrogen Plant Challenge," Hydrocarbon Engineering, July 2005.

59. Fujiwara, S. et al., "Hydrogen production by high temperature electrolysis with nuclear reactor," Progress in Nuclear Energy, Vol. 50, pp. 422-426, 2008.

60. Borhan, A., and Liepa, M. A., "High Temperature Steam Electrolysis: Technical and Economic Evaluation of Alternative Process Designs," Int. J. Hydrogen Energy, Vol. 11, No. 7, pp. 435-442, 1986.

61. Harvego, E. A., McKellar, M. G., Sohal, M. S., O’Brien, J. E., and Herring, J. S., "System Evaluation and Economic Analysis of a Nuclear Reactor Powered High Temperature Electrolysis Hydrogen Production Plant," Journal of Energy Resources Technology, 2010.

62. U.S. DOE Hydrogen Program Website, DOE H2A Analysis,

http://www.hydrogen.energy.gov/h2a analysis.html.

63. Ivy, J., "Summary of Electrolytic Hydrogen Production," NREL Report NREL/MP-560-36734, September, 2004.

64. Spath, P. L., and Mann, M. K., "Life Cycle Assessment of Hydrogen Production via Natural Gas Steam Reforming," NREL/TP-570-27637, 2001.

65. National Energy Board, “Canada's Oil Sands: Opportunities and Challenges to 2015: An Update," June, 2006.

66. Bergerson, J., and Keith, D., "Life Cycle Assessment of Oil Sands Technologies," Alberta Energy Futures Project, Paper No. 11, November, 2006.

67. Harvego, E. A., Mckellar, M. G., and O’Brien, J. E., "System Analysis of Nuclear-Assisted Syngas Production from Coal," 4th Int. Topical Mtg. on High Temperature Reactor Technology, paper\# HTR2008-58085, Washington, DC, Sept. 2008.

68. Scott, D. S., Smelling Land: The Hydrogen Defense Against Climate Catastrophe," Canadian Hydrogen Assoc., 2007.

69. Kreith, F., "Fallacies of a Hydrogen Economy: A Critical Analysis of Hydrogen Production and Utilization," Journal of Energy Resources Technology, Vol. 126, No. 4, pp. 249256, Dec. 2004.

70. U. S. Department of Energy, Transportation Energy Data Book, Edition 28, 2009.

71. U. S. Energy Information Administration, Annual Energy Outlook 2009, Supplemental Tables, 2009.

72. Norsk Hydro Fact Sheet, Atmospheric Electrolyzers, 2008.

73. Walters, L., Wade, D., and Lewis, D., "Transition to a Nuclear/Hydrogen Energy System," The Nuclear Engineer, Vol. 43, No. 6, 2002.

74. U. S. Energy Information Administration, Electric Power Annual, 2008. 